\title{
What does a cue do? Comparing phonological and semantic cues for picture naming in aphasia
}

Article

Accepted Version

Meteyard, L. and Bose, A. (2018) What does a cue do?

Comparing phonological and semantic cues for picture naming in aphasia. Journal of Speech, Language, and Hearing Research, 61 (3). pp. 658-674. ISSN 1558-9102 doi: https://doi.org/10.1044/2017_JSLHR-L-17-0214 Available at https://centaur.reading.ac.uk/75215/

It is advisable to refer to the publisher's version if you intend to cite from the work. See Guidance on citing.

To link to this article DOI: http://dx.doi.org/10.1044/2017_JSLHR-L-17-0214

Publisher: ASHA

All outputs in CentAUR are protected by Intellectual Property Rights law, including copyright law. Copyright and IPR is retained by the creators or other copyright holders. Terms and conditions for use of this material are defined in the End User Agreement.

www.reading.ac.uk/centaur 
Central Archive at the University of Reading

Reading's research outputs online 
$\underline{\text { http://jslhr.pubs.asha.org/journal.aspx }}$

Online ISSN: 1558-9102

Print ISSN: 1092-4388

What does a cue do? Comparing phonological and semantic cues for picture naming in aphasia

Lotte Meteyard

Arpita Bose

To cite this article: Meteryard, L. \& Bose, A. (in-press). What does a cue do? Comparing phonological and semantic cues for picture naming in aphasia. Journal of Speech Language and Hearing Research. 
Publisher: American Speech and Hearing Association

Journal: Journal of Speech, Language, and Hearing Research (JSHLR)

Running Head: Cueing in aphasia

What does a cue do? Comparing phonological and semantic cues for picture naming in aphasia

Lotte Meteyard

Arpita Bose

Department of Clinical Language Sciences

University of Reading

United Kingdom

Keywords: Cueing, phonology, semantic, naming, lexical variables.

Corresponding author:

Arpita Bose, Ph.D.

Department of Clinical Language Sciences,

School of Psychology and Clinical Language Sciences,

University of Reading, Reading, UK.

Email: a.bose@ reading.ac.uk 


\begin{abstract}
Purpose: Impaired naming is one of the most common symptoms in aphasia, often treated with cued picture naming paradigms. It has been argued that semantic cues facilitate the reliable categorisation of the picture, and phonological cues facilitate the retrieval of target phonology. To test these hypotheses, we compared the effectiveness of phonological and semantic cues in picture naming for a group of individuals with aphasia. To establish the locus of effective cueing, we also tested whether cue type interacted with lexical and image properties of the targets.
\end{abstract}

Method: Individuals with aphasia $(n=10)$ were tested with a within-subject design. They named a large set of items $(n=175)$ four times. Each presentation of the items was accompanied by a different cueing condition (phonological, semantic, non-associated word and tone). Item level variables for the targets (i.e., phoneme length, frequency, imageability, name agreement and visual complexity) were used to test the interaction of cue type and item variables. Naming accuracy data was analysed using generalised linear mixed effects models.

Results: Phonological cues were more effective than semantic cues, improving accuracy across individuals. However, phonological cues did not interact with phonological or lexical aspects of the picture names (e.g., phoneme length, frequency). Instead, they interacted with properties of the picture itself (i.e., visual complexity), such that phonological cues improved naming accuracy for items with low visual complexity.

Conclusions: The findings challenge the theoretical assumptions that phonological cues map to phonological processes. Instead, phonological information benefits the earliest stages of picture recognition, aiding the initial categorization of the target. The data help to explain why patterns of cueing are not consistent in aphasia, i.e., it is not the case that phonological impairments always benefit from phonological cues and semantic impairments form semantic cues. A substantial amount of the literature in naming therapy focuses on picture naming paradigms. Therefore, the results are also critically important for rehabilitation, allowing for therapy development to be more rooted in the true mechanisms through which cues are processed. 


\section{Introduction}

Impaired naming is the most common symptom of word production difficulties for people with aphasia (PWA). Cueing is a ubiquitous technique used both in assessment and therapy to ameliorate naming impairments (Laine \& Martin, 2006). A cue is a piece of relevant linguistic information presented once, prior to the individual attempting to name the target or after a failed production attempt. Typical cues are phonological (the first sound, e.g. "k" for cup) or semantic (a related word, e.g. "purr" for cat) (Heath et al., 2012; Nickels, 2002; Li \& Williams, 1990). If the cue is effective, it will facilitate word production and result in more accurate naming (Nickels \& Best, 1996). In assessment, cueing has been used to establish the nature of the naming impairments and when applied systematically over a long period of time and often as a hierarchy (e.g. first sound, first syllable, whole word), cueing becomes a therapeutic intervention (Nickels \& Best, 1996). Numerous therapies for naming utilize cues in the context of picture naming (e.g., Best, Greenwood, Grassly, Herbert, Hickin \& Howard, 2013; Kiran \& Bassetto, 2008; Leonard, Rochon \& Laird, 2008; Van Hees, Angwin, McMohan \& Copland, 2013).Despite the long history of use, there is no clear understanding of how, specifically, cues improve naming performance for PWA (Heath et al., 2012; Lorenz \& Nickels, 2007; Pellet Cheneval, Bonnans, \& Laganaro, 2017).

Irrespective of theoretical models, it is widely accepted that naming an object involves at least two stages: a) retrieval of the semantic information, and b) attaching form to the selected word ${ }^{1}$ (Schwartz, 2013). A simple hypothesis is that phonological and semantic cues support the retrieval of phonological and semantic information for a target word,

\footnotetext{
1 Beyond this basic framework there are many differences amongst the current models, with disagreements regarding the specifics within semantic and phonological levels, as well as discreteness and interactivity between these stages (Foygel \& Dell, 2000; Levelt, Roelofs, \& Meyer, 1999; Rapp \& Goldrick, 2000). For example, whilst Dell and colleagues (Dell et al., 1997) generally refer to lexical units as word units, the term is often used interchangeably with the 'lemma' of Levelt and colleagues' model (Levelt et al., 1999). There is also debate concerning the existence of intermediary representation between semantics and phonology (e.g. Caramazza, 1997). Within this class of models, some propose the discreetness of the stages (Levelt et al., 1999), whilst others postulate an interactive flow of information between them (Foygel \& Dell, 2000; Rapp \& Goldrick, 2000).
} 
respectively (e.g., Cuetos, Aguado, \& Caramazza, 2000; Howard \& Gatehouse, 2006; Jefferies \& Lambon Ralph, 2006). Similarly, a linked hypothesis is that phonological cues should remediate phonological impairments and semantic cues should remediate semantic impairments (e.g., Hickin, Best, Herbert, Howard, \& Osborne, 2002; Van Hees, Angwin, McMahon, \& Copland, 2013). Although it has been shown that individuals who experience successful facilitation with cueing during assessment also respond to cue based therapy (Hickin et al., 2002), there are few reliable correlations between individual patient profiles and response to cueing therapy (Lorenz \& Ziegler, 2009; Wisenburn \& Mahoney, 2009). This may be due to a combination of heterogeneous aphasic profiles and small neuropsychological sample sizes. To mitigate these difficulties, a few studies have used within-subject designs (e.g., Davis \& Pring, 1991; Lorenz \& Ziegler, 2009; Van Hees et al., 2013).

The provision of cues during picture naming has been compared to repetition priming (Martin \& Laine, 2000). That is, cues provide a short-term benefit from repeated presentations with a specific target item and the association this creates in a particular task (Logan, 1990). Beyond immediate facilitation, cues can lead to improved naming of target items at longer lags, e.g., more than 6 intervening items, 10 minutes (Heath et al., 2012; 2013). There is now a consensus that phonological and semantic therapies are equally effective (Lorenz \& Ziegler, 2009); the difference between them is often 'overstated' (Davis \& Pring, 1991). This is likely because word phonology is activated in semantic tasks and semantics is activated in phonological tasks, especially in picture naming where the picture stimulus activates conceptual and semantic information (e.g., Howard, Hickin, Redmond, Clark \& Best, 2006).

There was early evidence that phonological cues help to specify a semantic target for the picture, which in turn aids the selection of a specific phonological form (Stimely \& Noll, 1991; Li \& Williams, 1991). In healthy adults, the presence of linguistic information (e.g., a 
verbal label) improves categorization and learning of visual stimuli (Lupyan, 2008). Thus, in both healthy and impaired language processing, exposure to target related phonology improves categorization of target stimuli such as pictures. In the few studies that have directly compared phonological and semantic cues (i.e. within-subjects), some common patterns emerge. Whilst both phonological and semantic cues can be effective (sometimes equally across a group, Stimely \& Noll, 1991), phonological cues tend to be effective for more individuals (Van Hees et al., 2013; Lorenz \& Ziegler, 2009; Li \& Williams, 1991). It appears likely that phonological cues facilitate both the visual categorization of the picture as well as priming output phonology, making them more useful in picture naming than semantic cues. For semantic cues, pre-exposure to the picture alongside a semantic task (i.e., propertypicture verification such as verbal presentation "Does it purr?" with a picture of a cat) provided both short and long-term facilitation of picture naming (Heath et al., 2012; 2013). Under this description, perceptual and/or lexico-semantic processing of the picture is made more efficient by pre-exposure, and this improves naming.

To recap, naming a picture means to establish a reliable categorization of the picture (i.e. stable semantic information) and produce the associated target specific output phonology. Evidence suggests that semantic as well as phonological cues improve picture naming. However, the precise mechanism remains unclear. Yet the literature points towards an explanation where cues make the form-meaning mapping more reliable, rather than selectively improving a phonological or semantic stage of processing. For example, cutting across classical aphasia categories, it has been shown that individuals with better semantic processing and worse output phonology benefit from naming therapy (Best et al., 2013; Howard et al., 2006). These are precisely the individuals that can make use of cue information to improve the mapping from form to meaning and (re)learn target phonology. 
Our attempts to improve word production can be substantially improved by understanding why and how cues facilitate naming in aphasia. A fruitful way to address this question may be to use variation in the lexical properties of items. For example, words differ along a of range properties (e.g., word frequency, imageability, length) as do pictures (e.g., visual complexity, name agreement). A large body of psycho- and neuro-linguistic have shown the effect of specific lexical and image properties on word production (e.g., Indefrey, 2011). In healthy adults as well as in PWA, the general findings in the literature is that items are named more quickly and accurately when they are shorter, more frequent, more imageable and have high name agreement (e.g., Bose \& Schafer, 2017; Alario et al., 2004; Bonin, Peereman, Malardier, Méot, \& Chalard, 2003; Kittredge, Dell, Verkuilen \& Schwartz, 2008; Nickels \& Howard, 1995; Middleton \& Schwartz, 2010; Vitevitch \& Sommers, 2003). In addition, a retrospective analysis of items from three therapy studies found that highly imeagable words were named more accurately and required less cueing (Conroy, Snell, Sage \& Lambon Ralph, 2012).

To the best of our knowledge no study has explored the interaction between cue type (phonological or semantic) and target characteristics for PWA. Therefore, the aim of this study was to investigate the effect of cue condition (phonological vs. semantic) on the picture naming accuracy for a large set of items (175 pictures) for a mixed group of ten PWA. For additional experimental control and to aid interpretation, the study also included a neutral cue condition, to allow the effect of phonological and semantic cues to be properly compared and evaluated (Stimely \& Noll, 1991). The study also explored how cues interact with characteristics of the target words. Mixed model analysis allowed us to consider multiple predictor variables (condition, cue, and lexical variables) and account for variation in participant performance across conditions. Our research questions were: 
1. Are phonological and semantic cues equally effective in improving naming accuracy?

2. Is there an interaction between the cue type (phonological / semantic) and the lexical and image properties of the word?

If there is a simple mapping between cue type (phonological / semantic) and target properties, we should see the following: 2a. Semantic cues should facilitate the retrieval of conceptual and semantic information. We should see an interaction between semantic cues and imageability (i.e. words with lower imageability should benefit more from a semantic cue) and with name agreement (i.e. words with lower name agreement should benefit more from a semantic cue, e.g. Bose \& Schafer, 2017). 2b. Semantic and phonological cues should facilitate the retrieval of lexical information. We should see an interaction of semantic and phonological cues with frequency (i.e. words with lower frequency should benefit from both semantic and phonological cues). 2c. Phonological cues should facilitate the retrieval of phonological information. We should see an interaction between phonological cues and length (i.e. words that are longer should benefit from phonological cues).

\section{Method}

\section{Participant sample and Background Test Battery}

We recruited a mixed group of ten participants with aphasia (PWA, 6 male, 4 female). Age ranged from 42 to 85 years $(M=68.8, S D=13.75)$, education level from 13 to 16 years $(M=14.7, S D=1.16)$, and they were ten to 168 months $(M=64.3, S D=54.7)$ post-onset of stroke. Inclusion criteria for PWA were: a single left hemisphere cardiovascular accident as determined by neuroradiological and/ neurological examinations; a diagnosis of aphasia on standardized clinical tests (Boston Diagnostic Aphasia Examination, Goodglass, Kaplan, \& Barresi, 2001); at least eight months post-stroke; monolingual English speaker; no history of 
other neurological illness, psychiatric disorders or substance abuse; no visual field or sensory perceptual deficits based on the Reitan-Klove Sensory Perceptual Examination (Reitan \& Wolfson, 1993); and no other significant cognitive deficits.

For sample size calculation, power analysis was completed using data from Lorenz \& Ziegler (2009) that compared different cue types within-participants for a group of PWA, from which we could extract data for each individual to calculate mean, standard deviation and correlations (i.e. the correlation of participants' scores in the two conditions). We used equation 8 from Morris \& DeShon (2002) which takes the difference between the two condition means, and divides by the average standard deviation multiplied by a product of the correlation between conditions. This equation means that the resultant effect size can be interpreted like the more familiar between-subjects effect size calculation (see Morris \& DeShon, 2002, for details). Lorenz \& Ziegler (2009) found a benefit of phonological cueing within subjects (no cue mean proportion correct $\mathrm{M}=65.80$, $\mathrm{SD}=46.09$, cued additional proportion correct $\mathrm{M}=78.40, \mathrm{SD}=50.72$, correlation $=0.98)$ that gave an effect size of 1.30 . Within subject differences between proportion correct for word-form and semantic cues gave an effect size of 1.63 (word form $\mathrm{M}=29.30, \mathrm{SD}=11.97$; semantic $\mathrm{M}=8.80, \mathrm{SD}=4.29$, correlation $=-0.20$ ). When comparing cue conditions within subjects, a power of 0.95 would be achieved with samples of 8 or 6 respectively. Therefore, our sample should be sufficient to detect effects of cueing (i.e. when comparing phonological cues to semantic cues, or phonological cues to a control/absent cue condition). We were unable to complete an a-priori power analysis for the interaction between cue type and target variables, and the mixed effects analysis that includes the variances associated with the random effects (the groupings of participants and items) as data was not available for this. However, we anticipated that the number of items (175) presented to each participant for naming in each cue condition would be sufficient to detect main effects of relevant lexical variables. Given the large effect sizes of 
cueing from Lorenz \& Ziegler (2009) we were hopeful then that interactions between cue type and target variables could be detected. In addition, by manipulating cue type and target variables within subjects we were hopeful this would increase sensitivity to any interactions.

A comprehensive evaluation of participants' single word comprehension and production was performed using subtests from the Psycholinguistic Assessments of Language Processing in Aphasia (PALPA, Kay, Lesser, \& Coltheart, 1992); the 3-picture version of the Pyramids and Palm Trees Test (PPT, Howard \& Patterson, 1992) and the Philadelphia Naming Test (PNT, Roach, Schwartz, Martin, Grewal, \& Brecher, 1996). This battery measured overall picture naming abilities, input and output phonological abilities, and conceptual and lexico-semantic processing. Table 1 presents demographic information, aphasia type, severity and results of the background assessments for each of the PWA. Written informed consent procedures in accordance to the University Research Ethics Board were followed for all participants.

The group included four individuals with Broca's aphasia, two with transcortical motor aphasia, one with mixed aphasia, two with anomic aphasia, and one with Werincke's aphasia. BDAE aphasia severity ratings ranged from 1 to $3.5(M=1.75, S D=0.89 ; 1$ as most severe and 5 the least severe). They showed a wide range in picture naming abilities (PNT scores ranged from $20 \%$ to $87 \%$, Mean $=49.8, S D=23.6$ ). As a group they showed variable impairments both for input and output phonology but with better preserved conceptual and lexical semantics (PPT scores ranged from $83 \%$ to $98 \%$, Mean $=91.7, \mathrm{SD}=5.0$ ). See Table 1 . 
Table 1. Demographic details, aphasia type and severity, and performance (\% correct) on language tasks for People with Aphasia (PWA)

\begin{tabular}{|c|c|c|c|c|c|c|c|c|c|c|c|c|}
\hline Participants & JV & $\mathrm{JK}$ & $\mathrm{DH}$ & WR & EW & $\mathrm{FF}$ & $\mathrm{MH}$ & $\mathrm{AM}$ & $\mathrm{AW}$ & $\mathrm{CB}$ & Mean & $S D$ \\
\hline Age (years) & 78 & 62 & 56 & 42 & 75 & 76 & 73 & 85 & 83 & 58 & 68.80 & 13.75 \\
\hline Sex & $\mathrm{F}$ & M & $\mathrm{F}$ & M & M & M & $\mathrm{F}$ & M & $\mathrm{F}$ & M & & \\
\hline Education (years) & 13 & 14 & 15 & 16 & 14 & 15 & 16 & 16 & 15 & 13 & 14.70 & 1.16 \\
\hline Months post-stroke & 60 & 149 & 42 & 16 & 10 & 30 & 60 & 168 & 24 & 84 & 64.30 & 54.70 \\
\hline Aphasia type & Anomic & Broca's & Anomic & Broca's & Broca's & Wernicke's & TCM & Mixed & Broca's & TCM & & \\
\hline BDAE severity & 3 & 1 & 3.5 & 1 & 1.5 & 1.5 & 1 & 1 & 2 & 2 & 1.75 & 0.89 \\
\hline \multicolumn{13}{|c|}{ Naming and word production across modalities } \\
\hline Philadelphia Naming Test ${ }^{1}$ & 72 & 33.1 & 39 & 54.3 & 52.6 & 34 & 25 & 20 & 80.6 & 87 & 49.8 & 23.6 \\
\hline Number of Correct $(\mathrm{N}=175)$ & 126 & 58 & 68 & 95 & 92 & 60 & 44 & 35 & 141 & 150 & 86.9 & 40.8 \\
\hline \multicolumn{13}{|l|}{ Error profile (\#, proportion) } \\
\hline Formal errors & $10(0.20)$ & $4(0.03)$ & $8(0.07)$ & $3(0.04)$ & $0(0.00)$ & $4(0.03)$ & $3(0.02)$ & $8(0.06)$ & $2(0.06)$ & $0(0.00)$ & & \\
\hline Semantic errors & $6(0.12)$ & $46(0.39)$ & $24(0.22)$ & $33(0.41)$ & $10(0.12)$ & $18(0.16)$ & $25(0.19)$ & $11(0.08)$ & $13(0.38)$ & $17(0.68)$ & & \\
\hline Mixed errors & $1(0.02)$ & $5(0.04)$ & $4(0.04)$ & $4(0.05)$ & $5(0.06)$ & $0(0.00)$ & $0(0.00)$ & $0(0.00)$ & $3(0.09)$ & $0(0.00)$ & & \\
\hline Nonword errors & $10(0.20)$ & $5(0.04)$ & $3(0.03)$ & $5(0.06)$ & $3(0.04)$ & $57(0.50)$ & $0(0.00)$ & $58(0.41)$ & $5(0.15)$ & $2(0.08)$ & & \\
\hline Unrelated errors & $0(0.00)$ & $14(0.12)$ & $5(0.03)$ & $1(0.01)$ & $8(0.10)$ & $8(0.07)$ & $\begin{array}{c}0(0.00) \\
103\end{array}$ & $31(0.22)$ & $4(0.12)$ & $1(0.04)$ & & \\
\hline $\begin{array}{c}\text { Miscellaneous } \\
\text { Across Modality ( \#53 PALPA }{ }^{2} \text { ) }\end{array}$ & $22(0.45)$ & $43(0.37)$ & $63(0.59)$ & $34(0.43)$ & $57(0.69)$ & $28(0.24)$ & $(0.59)$ & $32(0.23)$ & $7(0.21)$ & $5(0.2)$ & & \\
\hline \#53 Repetition & 92.5 & 92.5 & 97.5 & 100 & 92.5 & 95 & 88 & 65 & 95 & 97.5 & 91.6 & 9.9 \\
\hline \#53 Naming & 75 & 30 & 42.5 & 55 & 62.5 & 40 & 30 & 25 & 85 & 95 & 54.0 & 24.7 \\
\hline \multicolumn{13}{|l|}{$\begin{array}{l}\text { Input and output phonology } \\
\# 2 \text { PALPA: Real word minimal pair } \\
\text { discrimination }\end{array}$} \\
\hline Same & 97.22 & 94.44 & 97.22 & 97.22 & 100 & 100 & 97 & 77.8 & 81 & 97.2 & 93.9 & 7.8 \\
\hline Different & 80.55 & 58.33 & 72.22 & 83.33 & 88.8 & 83.3 & 86 & 47.2 & 69 & 97.2 & 76.6 & 15.1 \\
\hline $\begin{array}{l}\text { \#4 PALPA: Minimal pair requiring } \\
\text { picture selection }\end{array}$ & 100 & 95 & 87.5 & 97.5 & 72.5 & 88 & 93 & 77.5 & 82.5 & 100 & 89.4 & 9.5 \\
\hline \# 9 PALPA: Word repetition & 85 & 66.25 & 95 & 98.75 & 94 & 96.3 & 100 & 20 & 62.5 & 100 & 81.8 & 25.7 \\
\hline High imageability & 92.5 & 77.5 & 95 & 100 & 97.5 & 97.5 & 100 & 35 & 75 & 100 & 87.0 & 20.4 \\
\hline Low imageability & 77.5 & 55 & 95 & 97.5 & 95 & 95 & 100 & 5 & 50 & 100 & 77.0 & 31.4 \\
\hline High frequency & 90 & 72.5 & 97.5 & 100 & 97.5 & 97.5 & 100 & 20 & 52.5 & 100 & 82.8 & 27.0 \\
\hline
\end{tabular}




\begin{tabular}{|c|c|c|c|c|c|c|c|c|c|c|c|c|}
\hline Low frequency & 80 & 60 & 92.5 & 97.5 & 90 & 95 & 100 & 20 & 72.5 & 100 & 80.8 & 25.0 \\
\hline \# 8 PALPA: Nonword repetition & 23.33 & 53.33 & 76.67 & 76.66 & 66.6 & 87 & 57 & 3.3 & 40 & 83.3 & 56.7 & 27.4 \\
\hline 1-syllable & 30 & 40 & 80 & 70 & 40 & 90 & 50 & 10 & 10 & 80 & 50.0 & 29.1 \\
\hline 2-syllable & 30 & 50 & 60 & 80 & 80 & 80 & 70 & 0 & 60 & 80 & 59.0 & 26.4 \\
\hline 3-syllable & 10 & 70 & 90 & 80 & 80 & 90 & 50 & 0 & 50 & 90 & 61.0 & 33.1 \\
\hline \multicolumn{13}{|c|}{ Conceptual and lexico-semantic processing } \\
\hline Pyramids and Palm Trees ${ }^{3}$ & 96.15 & 82.69 & 98.08 & 92.31 & 86.5 & 89 & 90 & 94.2 & 90.4 & 98 & 91.7 & 5.0 \\
\hline $\begin{array}{l}\text { \# } 47 \text { PALPA: Spoken word-picture } \\
\text { matching }\end{array}$ & 100 & 97.5 & 95 & 92.5 & 85 & 93 & 85 & 100 & 92.5 & 95 & 93.6 & 5.3 \\
\hline $\begin{array}{l}\text { \#49 PALPA: Auditory synonym } \\
\text { judgments }\end{array}$ & 85 & 70 & 88.33 & 76.66 & 81.6 & 86.7 & 86.7 & 53.3 & 85 & 88.3 & 80.2 & 11.1 \\
\hline High imageability & 93.33 & 80 & 96.67 & 80 & 99.7 & 90 & 96.7 & 63.3 & 96.7 & 100 & 89.6 & 11.8 \\
\hline Low imageability & 76.66 & 60 & 80 & 73.33 & 66.7 & 83.3 & 76.7 & 43.3 & 73.3 & 76.7 & 71.0 & 11.8 \\
\hline
\end{tabular}

1 Philadelphia Naming Test (Roach et al., 1996); ${ }^{2}$ Psycholinguistic Assessments of Language Processing in Aphasia (Kay et al., 1992); ${ }^{3}$ Pyramid and Palm Trees Test (Howard \& Patterson, 1989); ${ }^{4}$ Transcortical Motor Aphasia. 


\section{Experimental manipulation}

A four-session computerized picture naming experiment was developed using the 175-item PNT (Roach et al., 1996). Four testing sessions manipulated cue condition (semantic vs. phonological) and cue type (valid phonological cue vs. control tone; valid semantically related cue vs. non-associated control). The sessions were blocked by condition (semantic and phonological): two sessions presented semantic cues and two sessions presented phonological cues. For each condition, testing was conducted over two sessions such that the items that were preceded by valid cues in one session were preceded by the control cues in the other session and vice versa. For the phonological cueing sessions, the auditory cue was either the first sound of the name of the picture (e.g., /ball/ $\rightarrow$ "b") in the valid condition or $1 \mathrm{KHz}$ pure-tone in the control condition. For semantic cueing, the valid auditory cue was a semantically related word (e.g., /candle/ $\rightarrow$ “wick") or a semantically nonassociated word in the control condition (e.g., /candle/ $\rightarrow$ “chop"). Experimental and therapeutic studies have used wide range of semantic cues (e.g., semantic attributes, concept properties, word associates, category memberships, etc). To generate our semantic cues, we used the first associates of the target items in the University of South Florida Word Association Norms (Nelson, McEvoy, \& Schreiber, 1998). This allowed a quantified measure for the semantic relationship, rather than subjective or intuited methods of generating semantic cues. Associated cues have also been shown to affect picture naming responses. If the first associate had the same phoneme onset with the target, we choose the next associate to ensure that there was no phoneme overlap with the cue and the target. Therefore, none of the semantic cues (associated or non-associated controls) had the same initial phoneme as the target. The non-associated control semantic cues were also matched to the related cues for word frequency, syllable length, and familiarity, and the non-associated semantic cues did not appear in the possible words in the association norms for that target word. The verbal cues 
were generated by a native English-speaking female and recorded in a sound-attenuated room. The pure tone was computer generated. The stimuli items are freely available on the Moss Aphasia Psycholinguistic Project Database (http://www.mappd.org/). Appendix A provides the stimuli with their lexical properties and the cues used in this experiment. A copy of the experiment software is available upon request.

A trial consisted of the presentation of the recorded auditory cue, followed by $750 \mathrm{~ms}$ of silence and then the target picture, which remained on the computer screen until a response was made or a maximum of 10 seconds had lapsed. A delay of $750 \mathrm{~ms}$ between cue and target was selected on the basis of a review of the aphasia picture naming literature. This literature shows delays ranging from $350 \mathrm{~ms}$ to 1400ms (Baum, 1997; Hagoort, 1997). Facilitation from cueing in picture naming has been observed for both positive and negative stimulus onset asynchronies (i.e. when the cue is presented both before or after the picture). However, a greater number of experimental studies have chosen a positive stimulus onset asynchrony (e.g., Indefrey, 2011) and demonstrated facilitation in picture naming from the cue being presented before the picture (e.g. Bose \& Buchanan, 2007). For that reason, we selected a duration of $750 \mathrm{~ms}$ that would allow sufficient time the cue to be processed but would not unnecessarily lengthen each trial (as participants were already completing four sessions of 175 naming trials). Other than occasional encouragement during the session, no other feedback was provided to the participants. The stimuli presentation was randomized within sessions, and validness and cue condition were counterbalanced across sessions. Therefore, for each participant there were a total of 700 picture naming trials $[175$ items $\mathrm{X} 2$ cue condition (semantic and phonological) X 2 cue types (valid vs. control)]. There was a gap of at least one week between each of the four sessions. These sessions were recorded with a high quality digital audio recorder and later transcribed for analysis. 


\section{Scoring and reliability}

We followed Roach et al. (1996) criteria to score the naming responses. The first complete non-fragmented naming attempt was scored as correct or incorrect. Criteria for identifying the first complete response were: ignoring instances of single phonemes or consonant + schwa and filler items (e.g. um, uh) altogether, incomplete items are judged on the basis of auditory cues (e.g. segment duration, a lack of downward or questioning intonation, no pause separating an item from the following attempt) which indicate selfinterruption. Responses were scored as correct if they replicated the target name. Addition or deletion of plural morphemes was accepted, as was the addition of modifiers such as "wishing well" for "well". All scoring was performed by the second author and a trained research assistant performed reliability checks for $35 \%$ of the sessions. The point-by-point inter-rater agreement was 96\% (Cohen's kappa, $\kappa=0.92)$, and disagreements were resolved by reviewing the scoring definitions and the transcripts (4\% of the data, 98 trials).

\section{Influence of word properties}

We selected target properties known to be influential in picture-naming: length (in phonemes), frequency (lemma), imageability, name agreement and visual complexity. Values for five target properties were obtained for each of the 175 PNT items (Table 2). Length (number of phonemes) is provided with the PNT materials. Log-transformed word frequency (lemma, per million) was retrieved from the CELEX lexical databases (Baayen, Piepenbrock, \& van Rijn, 1993). A full set of imageability ratings for the PNT stimuli were not available, so 38 healthy controls provided ratings for all 175 pictures, with the subsequent set of ratings consisting of the mean across all participants for each item. Name agreement values consisted of the mean accuracy of 20 control participants whose PNT naming results are provided in the Moss Aphasia Psycholinguistics Project Database (http://www.mappd.org/). Visual 
complexity values (based on image file size) were obtained from Székely \& Bates (2000). All properties were mean centered and scaled as z-scores to reduce collinearity.

Table 2. Descriptive statistics for lexical and image properties for the Philadelphia Naming Test items.

\begin{tabular}{lccc}
\hline \multicolumn{1}{c}{ Target property } & Mean & Range & SD \\
\hline Length in phonemes & 4.50 & $1.0-11.0$ & 1.77 \\
Log Lemma Frequency (per million) & 1.34 & $0.00-3.21$ & 0.63 \\
Imageability & 6.15 & $3.95-6.84$ & 0.42 \\
Name Agreement & 0.98 & $0.75-1.00$ & 0.05 \\
Visual Complexity & 217.50 & $59.00-526.00$ & 89.16 \\
\hline
\end{tabular}

\section{Analysis}

Generalised linear mixed effects models were used to model the data, implemented in R (R Core team, 2013) using the package lme4 (Bates, Maechler, Bolker \& Walker, 2014), lmerTest (Kuznetsova, Brockhoff \& Christensen, 2016) and effects (Fox, 2003). Accuracy was the dependent variable (binomial link function), giving log odds of producing a correct response as the model outcome. Random effects were used to model the experiment structure. Confidence intervals $(95 \% \mathrm{CI})$ were calculated using the Wald method. We fit random intercepts and correlated slopes for cue type varying across participants and items. Intercepts and slopes for items were perfectly correlated and slopes did not improve model fit relative to intercepts only $\left(X^{2}=0.3661, \mathrm{df}=2, p=0.83\right)$; thus we retained only random intercepts for items. Fixed effects for session and trial were not significant and did not improve model fit $\left(\operatorname{LogLik}\right.$ with Session $=-3259, X^{2}(1)=0, p>.25 ; \operatorname{LogLik}$ with Trial $=-3259, X^{2}(1)=0.64$, $p>.25)$. These were not included in further analysis. Models with fixed effects to test for cue, item properties and interactions of cue with item properties and Likelihood ratio tests comparing model fits are detailed below. 


\section{Results}

\section{Are phonological and semantic cues equally effective in improving naming accuracy?}

We evaluated whether cue type improved naming performance. Cue type was entered as a fixed effect with four levels: phonological cue, tone, semantic cue and non-associated control word. This significantly improved model fit over the null model (vs. random effects only; LogLik with Cue $\left.=-3231, X^{2}(3)=54.5, p<.001\right)$. The phonological cue condition significantly improved naming accuracy when compared against all other cues (all estimates >1.6; all 95\% CIs between 0.37 - 3.00, see Table 3 for multiple comparisons and Figure 1), no other cue types affected naming performance.

\section{Is there an interaction between the cue type and the item properties of the word?}

The phonological cue was the only cue type that affected naming performance, with other cue types showing equivalent performance to each other. To simplify further analysis we collapsed across the cue conditions that were equal (semantic, non-associated and tone) to create a cue factor with two levels, phonological cue vs. no phonological cue (i.e. all other cue conditions). Modeling cue as a factor with two levels did not differ to a model with cue type as four levels (LogLik with Cue as two levels $\left.=-3232, X^{2}(2)=0.11, p>.250\right)$ and provided a significantly better fit to the data than a model with random effects only (LogLik Random Effects model $=-3259, \operatorname{LogLik}$ with Cue as two levels $=-3232 ; X^{2}(1)=54.38$, $p<.001)$. We evaluated whether item properties affected naming accuracy by entering each property as a main effect. Each item variable showed a significant main effect on naming accuracy and a model including main effects for all item properties was a significantly better fit than a model with cue type alone (LogLik with Cue alone $=-3232$, LogLik with Item main effects $\left.=-3179, X^{2}(5)=104.23, p<.001\right)$. We tested the two-way interaction between each 
item property and cue, by adding interaction terms to a model with item properties as main effects $^{2}$.

Table 4 provides a summary of the final model. Items that were longer were named less accurately (slope estimate $=-0.39,95 \% \mathrm{CI}=-0.54--0.25$ ), items that were higher in imageability (estimate $=0.26,95 \% \mathrm{CI}=0.11-0.41)$ and name agreement (estimate $=0.15$, $95 \% \mathrm{CI}=0.04-0.26$ ) were named more accurately (see Table 4 and Figure 2). Frequency did not significantly affect naming accuracy (estimate $=0.16,95 \% \mathrm{CI}=-0.02-0.33$ ). The only item property to significantly interact with cue was visual complexity. The interaction between phonological cue and visual complexity gave a small improvement in model fit $\left(\right.$ LogLik with Item main effects $=-3179$, LogLik with Cue $x$ Visual Complexity $=-3178, X^{2}$ $(1)=3.44, p=.064)$. When a phonological cue was present, visual complexity influenced naming accuracy (slope estimate $=-0.25,95 \% \mathrm{CI}=-0.45--0.05$ ). When a phonological cue was not present, there was no effect of visual complexity (estimate $=-0.11,95 \% \mathrm{CI}=-0.25-$ 0.02). Figure 2 shows that items with higher visual complexity were named with similar accuracy whether a phonological cue was present or not. For items of lower visual complexity, the phonological cue causes these items to be named more accurately.

Table 5 provides a summary of the odds ratios for each participant for each predictor in the model. These odds ratios show us the likelihood of a correct response without the influence of any predictors (the odds ratio for the intercept), and the odds ratios for each

\footnotetext{
2 Following reviewer comments, we added a more complex random effects structure, entering random intercepts and correlated slopes for each item property varying over participants. This should better control for false positives in the model (Barr et al., 2013). When random intercepts and slopes were included the model showed signs of over-fitting, with perfect correlations between the intercept and slope variances for all item properties. This model also did not converge when random intercepts and correlated slopes were fit for imageability. We simplified by removing the intercepts (i.e. fitting slopes only) and testing against the maximal model (see Appendix C), until we achieved a simpler model that did not differ from the maximal model for goodness of fit. We also removed the random slope for Name Agreement as it had a variance of zero (i.e. did not explain any variance in the data); this model did not differ from the more complex random effects model $\left(X^{2}(9)=13.768, p=0.13\right)$. We report the results from this model in Table 4, and results from the more complex random effects model in Appendix C (note that the significance of fixed effect predictors do not differ between the models). To check this model fit to the data, we refit the model after removing data points for which standardized residuals were greater than $+/-2.5(38$ data points). The results for the model were the same, except that the main effect of Frequency was significant. This model is reported in Appendix B.
} 
predictor then tell us what increase or decrease in the odds of a correct naming response are present when we include specific predictors (e.g. a unit increase in length of the word, the presence of a phonological cue). Looking at the intercept values in Table 5, we see the variation in the naming ability for each participant (e.g. low odds of a correct response for participants $\mathrm{AM}, \mathrm{MH}$ and $\mathrm{FF}$; high odds of a correct response for participants $\mathrm{CB}, \mathrm{JV}$ and EW). Turning to the predictors, across participants the presence of a phonological cue almost doubles the likelihood of getting a correct naming response (1.92). An increase in length (i.e. one more phoneme) reduces the likelihood of a correct naming response by around a third ( -0.4). An increase in one unit of imageability increases the likelihood of a correct response by around a quarter $(\sim 0.25)$. For the interaction of visual complexity and the phonological cue, when a phonological cue is present an increase in visual complexity reduces the likelihood of a correct response by around a quarter $(\sim-0.25)$. As we saw in Figure 2, this is because items with low visual complexity benefit from a phonological cue whereas items with high visual complexity do not. 
Table 3. Generalised linear mixed effects model results with multiple comparisons for cue type

Key: For each Cue comparison, the reference condition is the one to the right of the 'vs'.

\begin{tabular}{lccccc}
\hline & \multicolumn{3}{c}{ Standard } & & \\
Fixed Effects & Estimate & Error & $\mathbf{9 5 \%}$ CI & $\mathbf{Z}$ & $\boldsymbol{p}^{1}$ \\
\hline Intercept & 1.02 & 0.45 & $-0.08-2.11$ & 2.27 & $0.023^{*}$ \\
Phonological Cue vs Semantic Cue & 1.69 & 0.50 & $0.37-3.00$ & 3.38 & $0.004^{*}$ \\
Phonological Cue vs Tone Control & 1.65 & 0.47 & $0.42-2.87$ & 3.54 & $0.002^{*}$ \\
Phonological Cue vs Non-associated & & & & & \\
Control & 1.69 & 0.50 & $0.37-3.00$ & 3.38 & $0.004^{*}$ \\
Semantic Cue vs Tone Control & -0.04 & 0.14 & $-0.41-0.32$ & -0.32 & 1 \\
Semantic Cue vs Non-associated Control & 0.00 & 0.09 & $-0.23-0.23$ & -0.01 & 1 \\
Non-associated Cue vs Tone Control & 0.04 & 0.14 & $-0.32-0.41$ & 0.31 & 1 \\
& & & & & \\
Random Effects & Variance & Correlation & & & \\
Items (intercept) & 0.68 & & & & \\
Participants (intercept) & 1.91 & & & & \\
Participant x Condition (slope) & 0.11 & -0.24 & & &
\end{tabular}


Table 4. Generalised linear mixed effects model results for phonological cue, target properties and their interactions.

\begin{tabular}{|c|c|c|c|c|c|}
\hline Fixed Effects & Estimate & $\begin{array}{c}\text { Standard } \\
\text { Error }\end{array}$ & $\begin{array}{c}\text { Wald 95\% } \\
\text { CI }\end{array}$ & $\mathbf{Z}$ & $p$ \\
\hline $\begin{array}{l}\text { Intercept } \\
\text { Phonological Cue vs No Phonological }\end{array}$ & 0.31 & 0.44 & $-0.55-1.18$ & 0.72 & 0.47 \\
\hline Cue & 0.65 & 0.09 & $0.48-0.82$ & 7.50 & $\mathrm{p}<0.001 *$ \\
\hline Length & -0.39 & 0.07 & $-0.54--0.25$ & -5.32 & $\mathrm{p}<0.001 *$ \\
\hline Frequency & 0.16 & 0.09 & $-0.02-0.33$ & 1.75 & $\mathrm{p}=0.08$ \\
\hline Imageability & 0.26 & 0.08 & $0.11-0.41$ & 3.42 & $\mathrm{p}<0.001^{*}$ \\
\hline Name Agreement & 0.15 & $0.0-6$ & $0.04-0.26$ & 2.74 & $\mathrm{p}=0.006^{*}$ \\
\hline $\begin{array}{l}\text { Visual Complexity x Phonological Cue } \\
\text { Visual Complexity x No Phonological }\end{array}$ & -0.25 & 0.10 & $-0.45--0.05$ & -2.47 & $\mathrm{p}=0.01 *$ \\
\hline Cue & -0.11 & 0.07 & $-0.25-0.02$ & -1.60 & $\mathrm{p}=0.11$ \\
\hline Random Effects & & Variance & SD & Correlation & \\
\hline \multicolumn{6}{|l|}{ Intercepts } \\
\hline Items & & 0.32 & 0.57 & & \\
\hline Participants & & 1.74 & 1.32 & & \\
\hline \multicolumn{6}{|l|}{ Slopes (varying over Participants) } \\
\hline Condition Phonological & & 0.29 & 0.54 & & \\
\hline Condition Semantic & & 0.14 & 0.37 & 0.77 & \\
\hline Length & & 0.01 & 0.12 & & \\
\hline Frequency & & 0.04 & 0.21 & & \\
\hline Imageability & & 0.03 & 0.17 & & \\
\hline $\begin{array}{l}\text { Visual Complexity x Phonological Cue } \\
\text { Visual Complexity x No Phonological }\end{array}$ & & 0.04 & 0.19 & & \\
\hline Cue & & 0.01 & 0.12 & 1.00 & \\
\hline
\end{tabular}

Key: For each Cue comparison, the reference condition is the one to the right of the 'vs'.

$\mathrm{R}$ model equation: Accuracy $\sim(1+$ Condition|Subject $)+(1 \mid$ Word $)+$ Phonological Cue + zLength + zFrequency + zImageability + zNameAgreement + Phonological Cue: zVisualComplexity.

Confidence intervals calculated with confint.merMod() function in lme4 


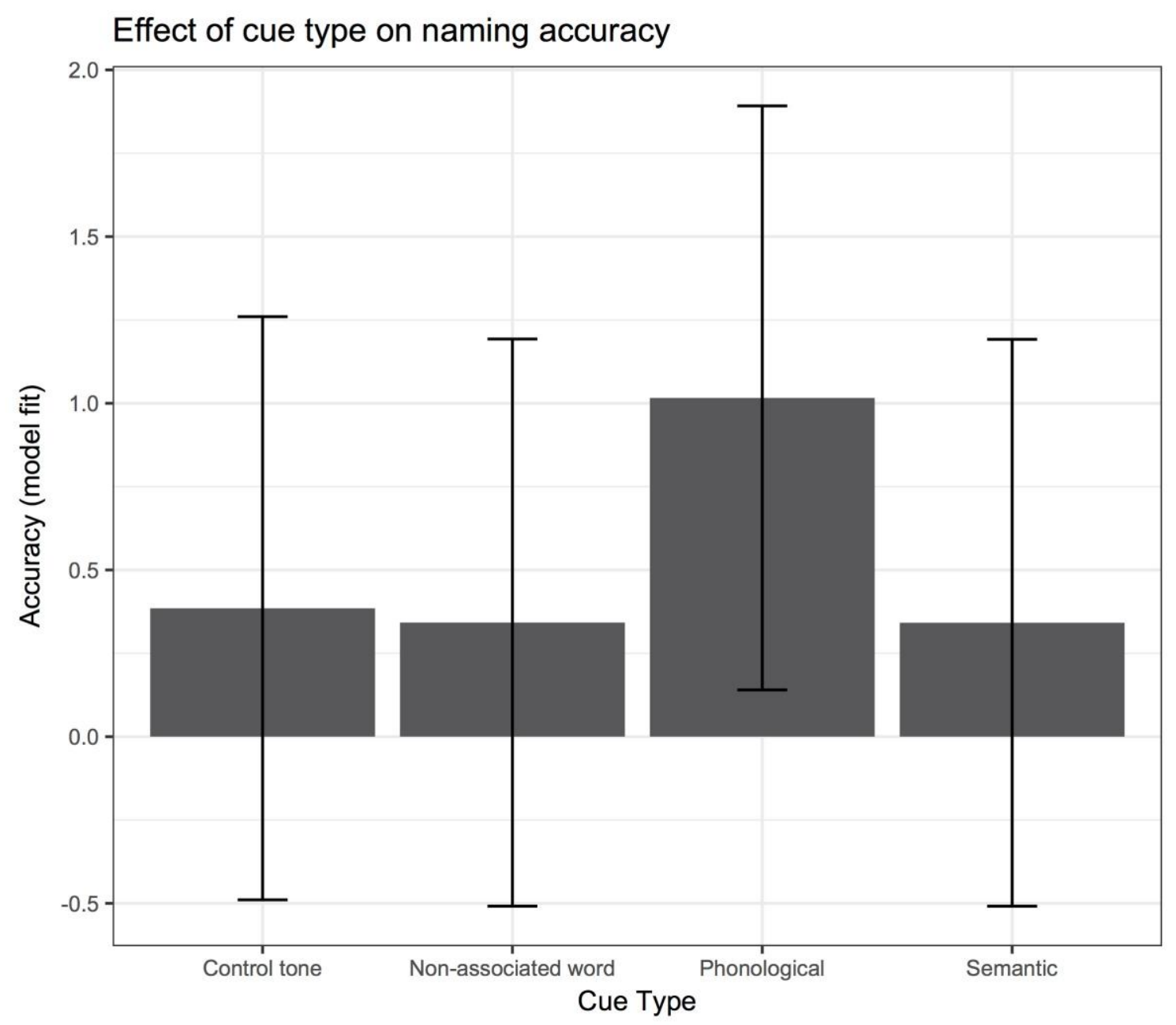

Figure 1. Effect of cue type on naming accuracy. The y axis presents fitted values from the generalized (logistic) linear mixed effect model. Error bars are $95 \%$ confidence intervals. 
a) Partial Effect for Length

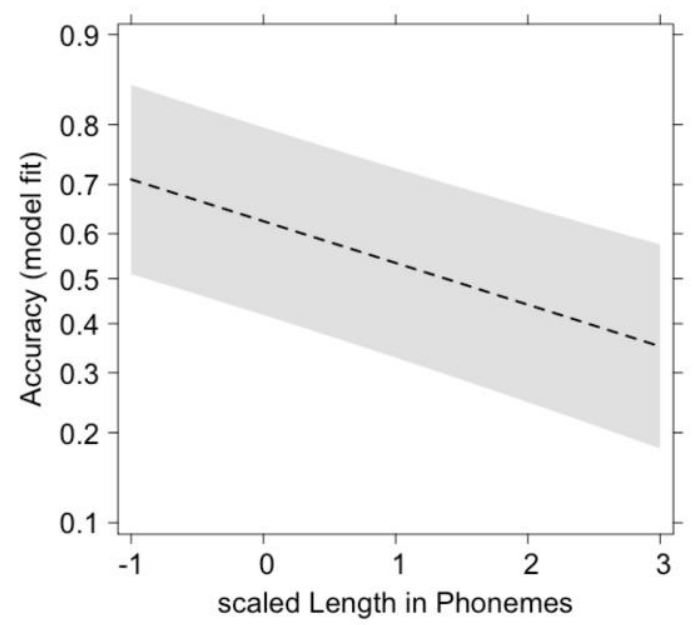

c) Partial Effect for Imageability

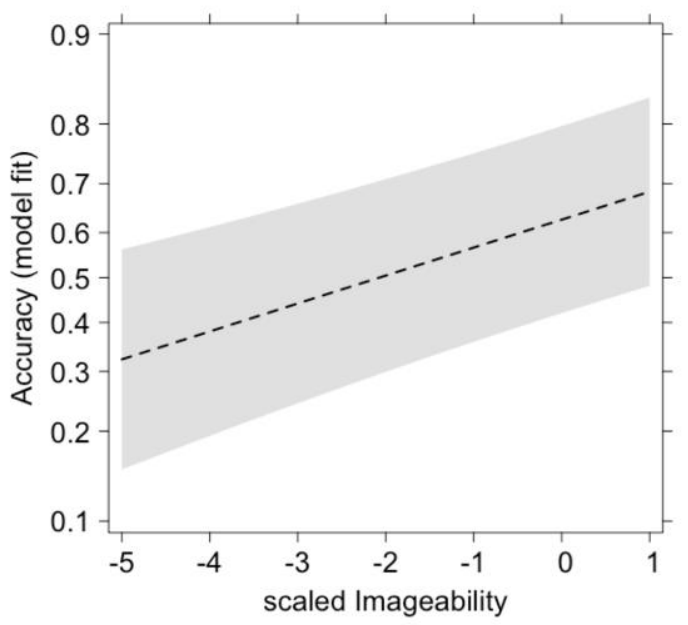

b) Partial Effect for Frequency

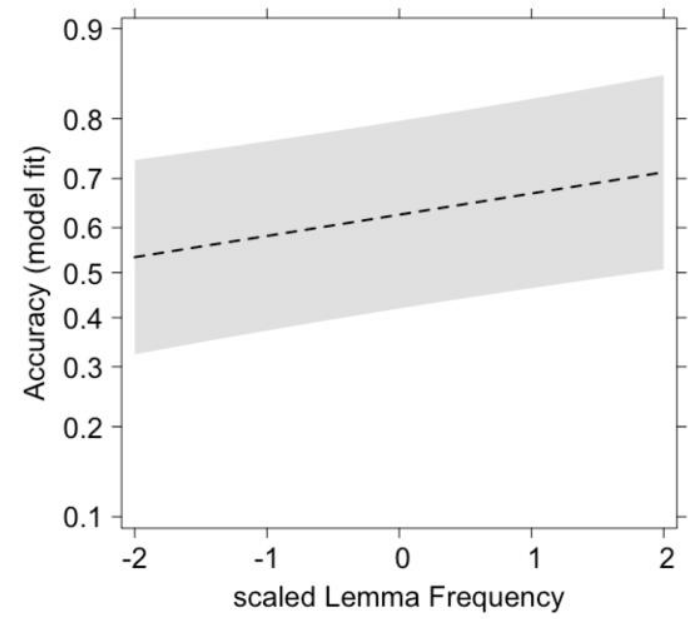

d) Partial Effect for Name Agreement

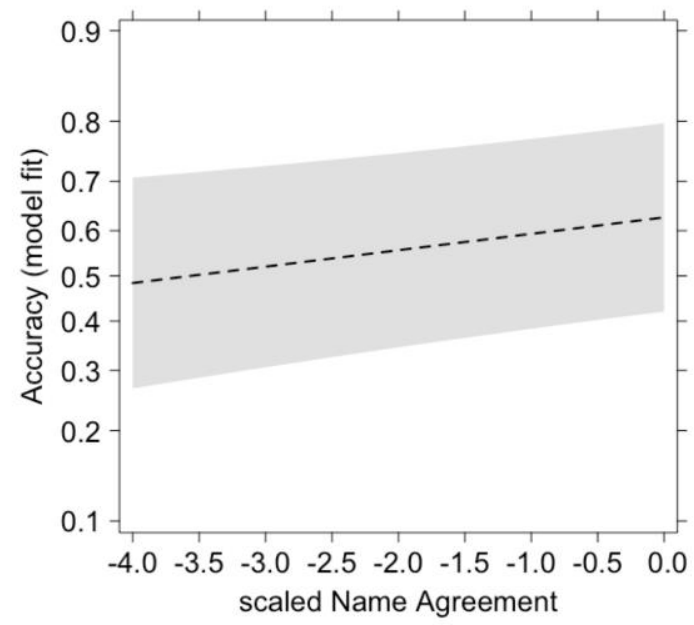

e) Partial Effect for Phonological Cue $x$ Visual Complexity No $\stackrel{\text { Phonological.Cue }}{\text { Yes }}$

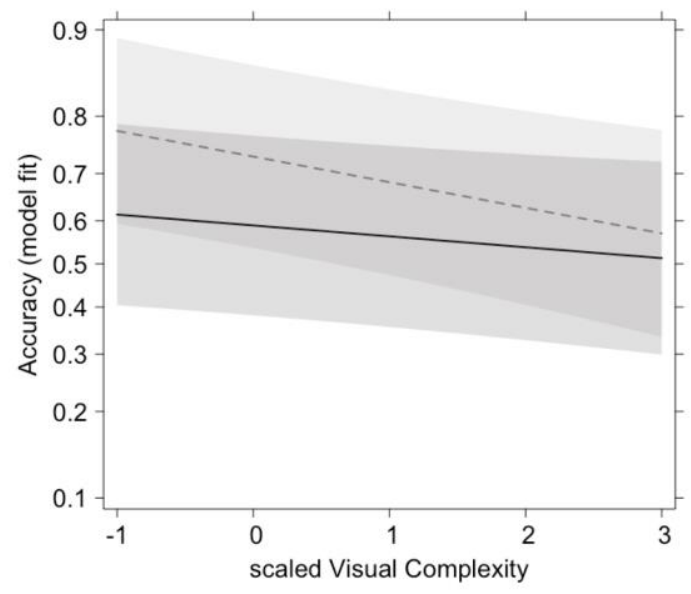

Figure 2. Partial effects plots for the main effects of Length, Frequency, Imageability and Name Agreement, and the interaction of Phonological Cue with Visual Complexity. The y axis presents fitted values from the generalized (logistic) linear mixed effect model. The $x$ axis presents scaled scores for each lexical variable (z scores). Error bars are $95 \%$ confidence intervals computed over subject averages. 
Table 5. Odds ratios for each participant (taken from model coefficients).

\begin{tabular}{|c|c|c|c|c|c|c|c|c|}
\hline Participant & Intercept & $\begin{array}{l}\text { Phonological } \\
\text { Cue } \\
\end{array}$ & Length & Frequency & Imageability & $\begin{array}{l}\text { Name } \\
\text { Agreement }\end{array}$ & $\begin{array}{l}\text { Visual } \\
\text { Complexity } \\
\mathbf{x} \\
\text { Phonological } \\
\text { Cue } \\
\end{array}$ & $\begin{array}{l}\text { Visual } \\
\text { Complexity } \\
\text { x No } \\
\text { Phonological } \\
\text { Cue } \\
\end{array}$ \\
\hline$J V$ & 3.62 & 1.92 & -0.42 & 0.17 & 0.03 & 0.15 & -0.2 & -0.08 \\
\hline$J K$ & 0.86 & 1.92 & -0.4 & 0.27 & 0.44 & 0.15 & -0.27 & -0.12 \\
\hline$D H$ & 0.75 & 1.92 & -0.35 & 0.15 & 0.16 & 0.15 & 0.03 & 0.06 \\
\hline$W R$ & 2.3 & 1.92 & -0.42 & 0.1 & 0.26 & 0.15 & -0.12 & -0.03 \\
\hline$E W$ & 3.88 & 1.92 & -0.37 & -0.16 & 0.21 & 0.15 & -0.17 & -0.06 \\
\hline$F F$ & 0.56 & 1.92 & -0.55 & 0.44 & 0.18 & 0.15 & -0.31 & -0.15 \\
\hline$M H$ & 0.36 & 1.92 & -0.24 & 0.17 & 0.22 & 0.15 & -0.44 & -0.23 \\
\hline$A M$ & 0.14 & 1.92 & -0.36 & 0.38 & 0.48 & 0.15 & -0.47 & -0.25 \\
\hline$A W$ & 4.4 & 1.92 & -0.31 & 0.09 & 0.2 & 0.15 & -0.38 & -0.19 \\
\hline$C B$ & 7.97 & 1.92 & -0.45 & -0.1 & 0.43 & 0.15 & -0.14 & -0.04 \\
\hline Average & & 1.92 & -0.387 & 0.151 & 0.261 & 0.15 & -0.247 & -0.109 \\
\hline
\end{tabular}

The odds ratio for the value of the intercept is the odds of a "success" (i.e. the odds of accurate naming) when $x=0$ (i.e. 0 values for the other predictors in the model, in this case target properties). The odds ratios for coefficients are the increase (or decrease) in the likelihood / odds of successful naming above the value of the intercept when you add one whole $\mathrm{x}$ value (i.e. unit increase in length; presence of phonological cue). 


\section{Discussion}

In a controlled experiment using within-subject comparison, phonological cues were found to be more effective both in comparison to a control cue and in comparison to semantic cues. This highlights that when task structure, cue provision and response demands were controlled, phonological cues were most effective. The literature shows varying results for which cue (phonological or semantic) is most effective in improving picture naming. Results range from no benefit, to cue to equivalent benefits, to phonological cues to be more effective (e.g., Drew \& Thompson, 1999; Lorenz \& Ziegler, 2009; Pellet Cheneval et al., 2013; Van Hees et al., 2013). Many therapy studies have demonstrated that phonological cues are not just effective in individuals with phonological processes impairments but also for individuals with semantic impairments. For example, Raymer et al. (1993) showed that four participants with semantic and lexical access impairment improved in naming therapy following phonological cueing. The findings of the current study corroborate recent data showing that phonological cues were more effective in improving picture naming than semantic cues (Lorenz \& Ziegler, 2009; Van Hees et al., 2013). Across participants, the presences of a phonological cue made a correct response almost twice as likely.

We also found that semantic cues were not effective when compared against control cue conditions. This is in contrast to a large body of therapy research which had shown semantic cues to be effective ways to improve picture naming, with some earlier studies claiming semantic approaches to be more effective than phonological cues (e.g., Boyle, 2004). This could stem from the type of semantic cue and the manner in which the cues were provided in our experiment. We provided word associate as semantic cues, whilst in semantic therapies cues that are provided could range from yes/no judgement about categorical and attributive information, descriptions, use of an object, and often for a single word a combination of cues are provided (Kiran \& Bassetto, 2008). Thus, the multiple sources of 
semantic information provided for semantic cues in a therapy context is in contrast to a single cue (i.e., word associate) delivered in our experiment. In addition, the word associates were presented auditorily prior to the picture without any opportunity to consider them actively. It is well established that cueing benefits are more effective when PWA engage with them more actively and deeply, be it semantic or phonological cues (e.g., Bose 2013; Hickin et al., 2002; Leonard et al., 2008). Future research testing within participants' comparison of types of semantic cues would shed further light into the differential benefits of various types of cues.

Based on the literature on the effect of lexical properties on picture naming, we anticipated that certain words (short, more frequent, highly imageable, high name agreement) would have greater partial activation and would need less cueing to generate accurate naming. We found positive effects for a number of variables - words that were shorter, more imageable and pictures with higher name agreement were all named more accurately. This is in line with previous literature (e.g., Bose \& Schafer, 2017; Kittredge et al., 2008; Middleton \& Schwartz, 2010) confirming the important role of both picture and word properties on accurate naming in aphasia. Critically however, the findings support the idea that properties affecting early stages of picture identification and lexical retrieval, such as name agreement and visual complexity, are influential in predicting accuracy in picture naming (e.g., Alario et al., 2004; Bose \& Schafer, 2017; Ellis \& Morrison, 1998; Vitkovitch \& Tyrrell, 1995). As images are essential materials for assessments and rehabilitation in aphasia, it is important to determine how image properties affect naming responses. An individual with aphasia may show poor naming performance because the pictures are poor, falsely inflating the measure of their impairment.

We found no interactions between the phonological cue and the majority of target variables, despite finding clear and stable main effects (any effect of frequency was likely unreliable, see Appendix C). Thus, predictions 2a-2c were not supported. This was surprising 
to us. We predicted that phonological cues would interact with length, since items that are longer are harder to retrieve (as reflected the in the main effect of length) and a phonological cue should directly support retrieval of target phonology. It may be that if phonological cues were provided following picture presentation or after a retrieval failure we may have seen the (in our mind) straightforward mapping between phonological cues and word length.

Visual complexity was the only variable that interacted with phonological cues. Specifically, when a phonological cue was present, items with lower visual complexity were named more accurately than items with high visual complexity. When a phonological cue was not present, there was no effect of visual complexity. Facilitative effects of low visual complexity on picture naming reaction times have been found in healthy individuals (Ellis \& Morrison, 1998; Vitkovitch \& Tyrrell, 1995), whilst other studies failed to find any effects of visual complexity (e.g., Bates et al., 2003; Bonin et al., 2003). In the healthy literature, longer reaction times to more complex pictures has been attributed to the added detail causing longer picture recognition processes (Ellis \& Morrison, 1998). Previous work with PWA has generally either failed to find any effect of visual complexity on output (Nickels \& Howard, 1995) or found an effect in the opposite direction, that is, more visually complex items were more likely to be produced correctly (Cuetos, Aguado, Izura \& Ellis, 2002). Cuetos et al. (2002) suggest that more detail assisted the recognition of the picture in their patients due to 'activation of more visual semantic material' (p. 363) aiding subsequent lexical retrieval. Our findings support this interpretation, since pictures with high visual complexity were named equally accurately whether a phonological cue was present or not. We found that items with less visual information (i.e. lower visual complexity) benefitted from a phonological cue. Thus, pictures of this kind may be hindering naming, as the visual input is sparse and provides less information for easy identification (in line with Cuetos et al, 2002). Phonological cues did not interact with other lexical variables (e.g. length in phonemes, 
frequency) which could suggest that phonological cues do not affect lexical or output phonology during picture naming - if phonological cues were facilitating the production of phonological information that is partially available, we predicted an interaction of phonological cues with length (i.e. phonological cues aiding the retrieval of longer words) or frequency (i.e. phonological cues aiding the retrieval of items of lower frequency). The finding for visual complexity could be attributed cues being presented prior to the picture. That is, the individual may not be sure that they are seeing an apple, a ball or a balloon, but the provision of the phonological information " $b a$ " beforehand rules out apple. Results may have been different if cues were presented after the picture had appeared, or only following a retrieval failure (as in standard assessments of picture naming). However, our data supports literature showing that phonological cues facilitate the mapping from picture concept to word form. In a recent study, Heath et al. (2013) suggested that phonological cues work to effect object recognition in the short term, and strengthen the links from semantics to phonology. During picture naming, we are asking people to recognize a picture and retrieve an appropriate name for that picture. If individuals cannot retrieve a name, provision of a phonological cue helps to constrain the 'search space' that the person is using when they look at the picture (Best et al., 2002; Bose \& Buchanan, 2007). In this way, the phonological information is fed back to the early stages of picture recognition, facilitating word retrieval by improving the specificity of conceptual information that is retrieved. This then feedsforward to lexical and word form retrieval and increases the likelihood of a correct naming response. This interpretation is in line with models of word production that allow for nonlinear, cascading of information between different levels of production (i.e. from phonology back to object recognition; see also Griffin \& Bock, 1998).

As pointed out by a reviewer, picture recognition errors are typically rare for individuals with aphasia - suggesting that picture recognition processes could be intact and the word 
retrieval difficulties are driven primarily by problems with accessing lexical information (i.e., lexico-semantic or phonological representations). However, the majority of the literature on picture naming in aphasia has focused on these lexical aspects of naming, rather than consideration of the picture and image properties. Bose \& Schafer (2017) showed that pictures with low name agreement resulted in higher error rates for a group of individuals with aphasia. Name agreement arguably involves early processes linked to picture recognition and the flow of information from visual/conceptual semantics to lexical retrieval. Our data shows that phonological cues support naming for pictures which have sparser visual information (i.e. low visual complexity). Whilst it may be the case that picture and object recognition is broadly intact for the majority of individuals with aphasia, if we assume a system that is highly interactive (see above) then lexical retrieval will be more sensitive to variations in the quality of information provided from the image. In other words, an individual can recognize the picture but if the visual information is sparse, noisy or degraded then lexical retrieval will be affected.

In summarize, our data reveals that phonological cues were more effective than semantic cues in improving naming accuracy across individuals. Phonological cues interacted with properties of the picture itself (i.e., visual complexity). The findings challenge the notion of a straightforward mapping from phonological cues to phonological processes. Instead, we see that phonological cues can support naming by feeding back to early picture recognition processes. The data help to explain why patterns of cueing are not consistent in aphasia, i.e., it is not the case that phonological impairments always benefit from phonological cues and semantic impairments form semantic cues. Phonological cues may be more broadly beneficial because they can support the conceptual and semantic information that is retrieved during picture recognition. 


\section{Acknowledgments}

We are indebted to all our participants for their enthusiasm and time for participation in this research. Data analysis was supported by a British Academy Skill Acquisition Grant (SQ120069) to LM.

\section{References}

Alario, F. X., Ferrand, L., Laganaro, M., New, B., Frauenfelder, U. H., \& Segui, J. (2004). Predictors of picture naming speed. Behavior Research Methods, Instruments, \& Computers, 36, 140-155.

Baayen, R. H., Davidson, D. J., \& Bates, D. M. (2008). Mixed-effects modeling with crossed random effects for subjects and items. Journal of Memory and Language, 59, 390412.

Baayen, R.H., \& Milin, P. (2010). Analyzing reaction times. International Journal of Psychological Research, 3(2).

Baayen, R., Piepenbrock, R., \& van Rijn, H. (1993). The CELEX lexical database (CDROM). Pennsylvania: Linguistic Data Consortium, University of Pennsylvania, PA.

Barr, D. J., Levy, R., Scheepers, C., \& Tily, H. J. (2013). Random effects structure for confirmatory hypothesis testing: Keep it maximal. Journal of Memory and Language, 68, 255-278.

Bates, D., Maechler, M., Bolker, B., \& Walker, S. (2014) lme4: Linear mixed-effects models using Eigen and S4. R package version 1.1-6. http://CRAN.Rproject.org/package $=1 \mathrm{me} 4$

Baum, S. (1997). Phonological, semantic and mediated priming in aphasia. Brain \& Language, $60,347-359$.

Best, W. Greenwood, A., Grassly, J., Herbert, R., Hickin, J., \& Howard, D. (2013). Aphasia rehabilitation: Does generalization from anomia therapy occur and is it predictable? A case series study. Cortex, 49, 2345-2357.

Best, W., Herbert, R., Hickin, J., Osborne, F., \& Howard, D. (2002). Phonological and orthographic facilitation of word-retrieval in aphasia: Immediate and delayed effects. Aphasiology, 16, 151-168.

Bonin, P., Peereman, R., Malardier, N., Méot, A., \& Chalard, M. (2003). A new set of 299 pictures for psycholinguistic studies: French norms for name agreement, image 
agreement, conceptual familiarity, visual complexity, image variability, age of acquisition, and naming latencies. Behavior Research Methods, Instruments, \& Computers, 35, 158-167.

Bose, A. (2013). Phonological naming therapy in jargon aphasia with neologisms: effects on picture naming and neologisms. International Journal of Language and Communication Disorders, 48, 582-595.

Bose, A., \& Buchanan, L. (2007). A cognitive and psycholinguistic investigation of neologisms. Aphasiology, 21, 726-738.

Bose, A., \& Schafer, G. (2017). Name agreement in aphasia. Aphasiology. 31, 1143-1165.

Boyle, M. (2004). Semantic feature analysis treatment for anomia in two fluent aphasia deficits in aphasia. Journal of Speech, Language, and Hearing Research, 42, 972989.

Conroy, P. J., Snell, C., Sage, K. E., \& Lambon Ralph, M. A. (2012). Using phonemic cueing of spontaneous naming to predict item responsiveness to therapy for anomia in aphasia. Archives of Physical Medicine and Rehabilitation, 93(1), S53-S60.

Cuetos, F., Aguado, G., \& Caramazza, A. (2000). Dissociation of semantic and phonological errors in naming. Brain and Language, 75, 451-460.

Cuetos, F., Aguado, G., Izura, C., \& Ellis, A. W. (2002). Aphasic naming in Spanish: predictors and errors. Brain and Language, 82, 344-365.

Davis, A., \& Pring, T. (1991). Therapy for word-finding deficits: More on the effects of semantic and phonological approaches to treatment with dysphasic patients. Neuropsychological Rehabilitation, 1, 135-145.

Drew, R. L, \& Thompson, C.K. (1999). Model-based semantic treatment for naming deficits in aphasia. Journal of Speech, Language, and Hearing Research, 42, 972-989.

Ellis, A. W., \& Morrison, C.M. (1998). Real age-of-acquisition effects in lexical retrieval. Journal of Experimental Psychology: Learning, Memory, \& Cognition, 24, 515-523.

Fox, J. (2003). Effect Displays in R for Generalised Linear Models. Journal of Statistical Software, 8(15), 1-27. URL http://www.jstatsoft.org/v08/i15/.

Foygel, D., \& Dell, G.S. (2000). Models of impaired lexical access in speech production. Journal of Memory and Language, 43, 182-216.

Goodglass, H., Kaplan, E., \& Barresi, B. (2001). Boston Diagnostic Aphasia Examination (BDAE). Baltimore, MD : Lippincott Williams \& Wilkins. 
Griffin, Z. M., \& Bock, K. (1998). Constraint, word frequency, and the relationship between lexical processing levels in spoken word production. Journal of Memory and Language, 38(3), 313-338.

Hagoort, P. (1997). Semantic priming in Broca's aphasics at a short SOA: No support for an automatic access deficit. Brain \& Language, 56, 287-300.

Heath, S., McMahon, K. L., Nickels, L., Angwin, A., MacDonald, A. D., van Hees, S., Johnson, K., McKinnon, E., \& Copland, D. A. (2012) Neural mechanisms underlying the facilitation of naming in aphasia using a semantic task: an fMRI study. $B M C$ Neuroscience, 13 98: 98.1-98.19. doi:10.1186/1471-2202-13-98

Heath, S., McMahon, K. L., Nickels, L., Angwin, A., MacDonald, A. D., van Hees, S., Johnson, K., McKinnon, E., Johnson, K., \& Copland, D. A. (2013). Facilitation of naming in aphasia with auditory repetition: an investigation of neurocognitive mechanisms. Neuropsychologia, 51, 1534-1548.

Hicken, J., Best, W., Herbert, R., Howard, D., \& Osborne, F. (2002). Phonological therapy for word-finding difficulties: A re-evaluation. Aphasiology, 16, 981-999.

Howard, D., \& Gatehouse, C. (2006). Distinguishing semantic and lexical word retrieval deficits in people with aphasia. Aphasiology, 20, 921-950.

Howard, D., \& Patterson, K. (1992). Pyramids and Palm Trees Test. Bury. St Edmunds: Thames Valley Test.

Howard, D., Hickin, J., Redmond, T., Clark, P., \& Best, W. (2006). Re-visiting semantic facilitation of word retrieval for people with aphasia: facilitation yes but semantic no. Cortex, 42, 946-962.

Indefrey, P. (2011). The spatial and temporal signatures of word production components: a critical update. Frontiers in Psychology, 2 (255), 1-16.

Jefferies, E., \& Ralph, M. A. L. (2006). Semantic impairment in stroke aphasia versus semantic dementia: a case-series comparison. Brain, 129, 2132-2147.

Kay, J., Lesser, R., \& Coltheart, M. (1992). Psycholinguistic assessments of language processing in aphasia. London: Psychology Press.

Kiran, S., \& Bassetto, G. (2008). Evaluating the effectiveness of semantic based treatment for naming deficits in aphasia: what works? Seminars in Speech and Language, 29, 7182. 
Kittredge, A., Dell, G., Verkuilen, J., \& Schwartz, M. F. (2008). Where is the effect of frequency in word production? Insights from aphasic picture-naming errors. Cognitive Neuropsychology, 25, 463-492.

Kuznetsova, A., Brockhoff, P.B. \& Bojesen, R.H. (2014). lmerTest: Tests for random and fixed effects for linear mixed effect models (lmer objects of lme4 package). $\mathrm{R}$ package version 2.0-6. http://CRAN.R-project.org/package=lme4

Laine, M., \& Martin, N. (2006). Anomia: Theoretical and clinical aspects. Hove, UK: Psychology Press.

Levelt, W. J., Roelofs, A., \& Meyer, A. S. (1999). A theory of lexical access in speech production. Behavioral and Brain Sciences, 22, 1-75.

Li, E.C., \& Williams, S.E. (1991). An investigation of naming errors following semantic and phonemic cueing. Neuropsychologia, 29, 1083-1093.

Logan, G. D. (1990). Repetition priming and automaticity: Common underlying mechanisms? Cognitive Psychology, 22, 1-35.

Lorenz, A., Ziegler, W. (2009). Semantic vs. Word Form Specific Techniques in Anomia Treatment: A Multiple Single Case Study. Journal of Neurolinguistics, 22, 515-537

Lorenz, A., \& Nickels, L. (2007). Orthographic cueing in anomic aphasia: How does it work? Aphasiology, 21, 670-686.

Lupyan, G. (2008). The conceptual grouping effect: Categories matter (and named categories matter more). Cognition, 108, 566-577.

Middleton, E. L., \& Schwartz, M. F. (2010). Density pervades: an analysis of phonological neighbourhood density effects in aphasic speakers with different types of naming impairment. Cognitive Neuropsychology, 27, 401-27.

Morris, S. B., \& DeShon, R. P. (1997). Correcting effect sizes computed from factor analysis of variance for use in meta-analysis.

Nelson, D. L., McEvoy, C. L., \& Schreiber, T. A. (1998). The University of South Florida word association, rhyme, and word fragment norms. http://www.usf.edu/FreeAssociation/.

Nickels, L. (2002). Theoretical and methodological issues in the cognitive neuropsychology of spoken word production. Aphasiology, 16, 3-19.

Nickels, L., \& Howard, D. (1995). Phonological errors in aphasic naming: Comprehension, monitoring and lexicality. Cortex, 31, 209 - 237.

Nickels, L., \& Best, W. (1996). Therapy for naming deficits (part I): Principles, puzzles and progress. Aphasiology, 10, 21-47. 
Pellet Cheneval, P., Bonnans, C., \& Laganaro, M. (2017). Does facilitation by phonological cuing in picture naming depend on the modality of the cue?. Aphasiology, DOI: $10.1080 / 02687038.2017 .1328102$

R Core Team (2013) R: A language and environment for statistical computing. R Foundation for Statistical Computing, Vienna, Austria. URL http://www.R-project.org/

Rapp, B., \& Goldrick, M. (2000). Discreteness and interactivity in spoken word production. Psychological Review, 107, 460-499.

Raymer, A.M., Thompson, C.K., Jacobs, B., \& Le Grand, H.R. (1993). Phonological treatment of naming deficits in aphasia: model-based generalization analysis. Aphasiology, 7, 27-53.

Reitan, R. M., \& Wolfson, D. (1993). The Halstead-Reitan neuropsychological test battery: Theory and clinical interpretation (2nd ed.). S. Tuscon, AZ: Neuropsychology Press.

Roach, A., Schwartz, M. F., Martin, N., Grewal, R.S., \& Brecher, A. (1996). The Philadelphia Naming Test: Scoring and Rationale. Aphasiology, 24, 121-133.

Schwartz, M. F. (2013). Theoretical analysis of word production deficits in adult aphasia. Philosophical Transactions of the Royal Society B, 369: 20120390.

Stimely, M.A., \& Noll, J. D. (1991). The effects of semantic and phonemic prestimulation cues on picture naming in aphasia. Brain and Language, 41, 496-509.

Székely, A., \& Bates, E. (2000). Objective visual complexity as a variable in studies of picture naming. Center for Research in Language Newsletter, 12, 3-33.

Van Hees, S., Angwin, A., McMahon, K., \& Copland, D. (2013). A comparison of semantic feature analysis and phonological components analysis for the treatment of naming impairments in aphasia. Neuropsychological Rehabilitation, 23, 102-132.

Vitevitch, M. S., \& Sommers, M. S. (2003). The facilitative influence of phonological similarity and neighborhood frequency in speech production in younger and older adults. Memory \& Cognition, 31, 491-504.

Vitkovitch, M., \& Tyrrell, L. (1995). Sources of disagreement in object naming. The Quarterly Journal of Experimental Psychology, 48, 822-848.

Wickham, R. (2009). ggplot2: elegant graphics for data analysis. Springer New York, 2009.

Wisenburn, B., \& Mahoney, K. (2009). A meta-analysis of word-finding treatments for aphasia. Aphasiology, 23, 1338-1352. 


\section{APPENDIX A}

This appendix provides the Philadelphia Naming Test (Roach et al., 1996) stimulus list with the lexical properties used in this study namely: length (in phonemes), frequency (lemma, per million), imageability, name agreement and visual complexity. We also provide the words used for semantically related cue and non-associated control cue.

\begin{tabular}{|c|c|c|c|c|c|c|c|c|}
\hline $\begin{array}{l}\text { Item } \\
\#\end{array}$ & $\begin{array}{l}\text { Target } \\
\text { Word }\end{array}$ & $\begin{array}{c}\text { Length } \\
\text { (Phonemes) }\end{array}$ & $\begin{array}{c}\text { Lemma } \\
\text { (base 10) } \\
\text { Log } \\
\text { Frequency } \\
\text { per } \\
\text { million } \\
\text { (CELEX) }\end{array}$ & Imageability & $\begin{array}{c}\text { Name } \\
\text { agreement }\end{array}$ & $\begin{array}{c}\text { Visual } \\
\text { complexity }\end{array}$ & $\begin{array}{l}\text { Semantically } \\
\text { related cue }\end{array}$ & $\begin{array}{c}\text { Semantically } \\
\text { non- } \\
\text { associated } \\
\text { control cue }\end{array}$ \\
\hline 1 & candle & 6 & 1.2041 & 6.54 & 1 & 129 & wick & chop \\
\hline 2 & ghost & 4 & 1.4914 & 5.29 & 1 & 211 & scary & insult \\
\hline 3 & dinosaur & 7 & 0.699 & 6.11 & 1 & 205 & extinct & pretend \\
\hline 4 & tree & 3 & 2.281 & 6.58 & 1 & 303 & sap & sill \\
\hline 5 & pen & 3 & 1.415 & 6.37 & 1 & 98 & ink & hedge \\
\hline 6 & scissors & 6 & 0.6021 & 6.58 & 1 & 138 & cut & late \\
\hline 7 & cane & 3 & 1 & 5.32 & 1 & 76 & walk & write \\
\hline 8 & comb & 3 & 0.699 & 6.11 & 1 & 330 & hair & rose \\
\hline 9 & thermometer & 10 & 0.7782 & 5.82 & 0.9 & 139 & temperature & dictionary \\
\hline 10 & well & 3 & 0.699 & 4.42 & 1 & 246 & bucket & letter \\
\hline 11 & grapes & 4 & 1 & 6.55 & 1 & 182 & vine & chick \\
\hline 12 & strawberries & 8 & 0.7782 & 6.66 & 0.9 & 199 & shortcake & illness \\
\hline 13 & bread & 4 & 1.8692 & 6.24 & 1 & 188 & loaf & hut \\
\hline 14 & football & 6 & 1.5185 & 6.58 & 1 & 174 & touchdown & permit \\
\hline 15 & pig & 3 & 1.6335 & 6.45 & 1 & 128 & ham & dent \\
\hline 16 & apple & 4 & 1.4771 & 6.55 & 1 & 120 & orchard & carpet \\
\hline 17 & hand & 4 & 2.8597 & 6.5 & 1 & 140 & glove & deer \\
\hline 18 & towel & 4 & 1.3424 & 6.37 & 0.8 & 160 & bath & rice \\
\hline 19 & lion & 4 & 1.3979 & 6.63 & 0.95 & 255 & roar & toll \\
\hline 20 & glass & 4 & 2.1614 & 5.84 & 1 & 173 & shatter & publish \\
\hline 21 & fork & 4 & 1.1761 & 6.45 & 1 & 118 & spoon & calf \\
\hline 22 & plant & 5 & 2.0828 & 6.03 & 0.95 & 215 & seed & match \\
\hline 23 & garage & 5 & 1.3979 & 5.82 & 1 & 386 & storage & partner \\
\hline 24 & can & 3 & 0.9542 & 4.71 & 1 & 159 & opener & stereo \\
\hline 25 & table & 5 & 2.3711 & 6.42 & 1 & 173 & chair & chin \\
\hline 26 & waterfall & 8 & 0.9031 & 6.42 & 1 & 365 & pool & plane \\
\hline 27 & king & 3 & 1.9956 & 5.73 & 1 & 334 & throne & rash \\
\hline 28 & boot & 3 & 1.5911 & 6.18 & 1 & 138 & kick & rash \\
\hline 29 & foot & 3 & 2.5132 & 6.37 & 1 & 90 & toe & cat \\
\hline 30 & chair & 3 & 2.1335 & 6.47 & 1 & 191 & table & road \\
\hline 31 & banana & 6 & 0.9031 & 6.84 & 1 & 175 & monkey & package \\
\hline 32 & ring & 3 & 1.6902 & 5.95 & 1 & 113 & diamond & lotion \\
\hline 33 & dice & 3 & 0.301 & 6.05 & 1 & 260 & gamble & refresh \\
\hline 34 & calendar & 8 & 0.9031 & 5.58 & 1 & 277 & date & buy \\
\hline 35 & knife & 3 & 1.6435 & 6.39 & 1 & 112 & fork & joke \\
\hline 36 & vest & 4 & 0.8451 & 6.03 & 1 & 185 & sweater & apple \\
\hline 37 & turkey & 5 & 0.699 & 6.26 & 1 & 304 & thanksgiving & fascinate \\
\hline 38 & rake & 3 & 0.301 & 5.84 & 0.95 & 148 & leaves & cub \\
\hline 39 & balloon & 5 & 0.7782 & 6.5 & 1 & 87 & helium & inferior \\
\hline 40 & duck & 3 & 1.1461 & 6.34 & 1 & 265 & quack & chess \\
\hline 41 & fireplace & 7 & 0.9542 & 6.32 & 1 & 185 & chimney & gamble \\
\hline 42 & pineapple & 7 & 0.4771 & 6.58 & 1 & 297 & fruit & tie \\
\hline
\end{tabular}




\begin{tabular}{|c|c|c|c|c|c|c|c|c|}
\hline 43 & fan & 3 & 1.2304 & 5.68 & 1 & 288 & air & eye \\
\hline 44 & window & 5 & 2.301 & 6.16 & 1 & 299 & pane & owl \\
\hline 45 & lamp & 4 & 1.5441 & 6.05 & 1 & 100 & desk & soil \\
\hline 46 & drum & 4 & 1.2041 & 6.03 & 1 & 345 & beat & cool \\
\hline 47 & skull & 4 & 1.3222 & 6.29 & 0.75 & 216 & brain & tool \\
\hline 48 & bridge & 4 & 1.8195 & 6.18 & 1 & 526 & river & women \\
\hline 49 & eskimo & 6 & 0.301 & 5.82 & 0.9 & 227 & arctic & filter \\
\hline 50 & $\operatorname{dog}$ & 3 & 2.0607 & 6.76 & 1 & 160 & pet & shoe \\
\hline 51 & iron & 4 & 1.8513 & 5.76 & 1 & 238 & crease & peep \\
\hline 52 & cheerleaders & 8 & 0 & 6.03 & 0.95 & 324 & football & golden \\
\hline 53 & snake & 4 & 1.3617 & 6.45 & 1 & 263 & bite & tide \\
\hline 54 & ambulance & 9 & 0.9542 & 6.53 & 0.9 & 373 & emergency & territory \\
\hline 55 & carrot & 5 & 0.9031 & 6.5 & 1 & 149 & vegetable & graduation \\
\hline 56 & sailor & 5 & 1.0792 & 5.84 & 0.95 & 138 & ship & core \\
\hline 57 & book & 3 & 2.6375 & 6.47 & 1 & 230 & library & orchestra \\
\hline 58 & bus & 3 & 1.8976 & 6.32 & 0.95 & 291 & tour & shell \\
\hline 59 & map & 3 & 1.6021 & 6.45 & 1 & 494 & directions & terminate \\
\hline 60 & squirrel & 7 & 0.7782 & 6.39 & 1 & 236 & acorn & mustard \\
\hline 61 & microscope & 9 & 0.9031 & 5.97 & 0.84 & 178 & biology & strategy \\
\hline 62 & bowl & 3 & 1.5185 & 6.27 & 0.85 & 157 & dish & fox \\
\hline 63 & van & 3 & 1.7634 & 6.18 & 0.95 & 296 & move & heart \\
\hline 64 & helicopter & 10 & 1.2041 & 6.47 & 1 & 231 & flying & crying \\
\hline 65 & bottle & 5 & 2.0645 & 6.39 & 0.95 & 100 & wine & team \\
\hline 66 & scarf & 5 & 1.0792 & 6.26 & 1 & 209 & wool & chop \\
\hline 67 & ball & 3 & 2.0453 & 6.37 & 1 & 226 & racquet & eating \\
\hline 68 & frog & 4 & 0.9542 & 6.47 & 1 & 179 & croak & gash \\
\hline 69 & cow & 2 & 1.6021 & 6.5 & 1 & 193 & moo & oar \\
\hline 70 & beard & 4 & 1.3979 & 6.11 & 1 & 399 & whiskers & finance \\
\hline 71 & glove & 4 & 1.2788 & 6.32 & 1 & 146 & hand & old \\
\hline 72 & owl & 2 & 0.8451 & 6.42 & 1 & 235 & hoot & soak \\
\hline 73 & pipe & 3 & 1.4914 & 5.63 & 1 & 139 & tobacco & stereo \\
\hline 74 & scale & 4 & 1.9138 & 4.24 & 0.94 & 239 & measure & friendly \\
\hline 75 & tent & 4 & 1.6435 & 6.58 & 1 & 168 & camping & chicken \\
\hline 76 & flashlight & 7 & 0.699 & 5.89 & 1 & 173 & battery & discover \\
\hline 77 & camel & 5 & 1.3979 & 6.19 & 1 & 184 & desert & blanket \\
\hline 78 & goat & 3 & 1.4472 & 6.24 & 1 & 202 & mountain & table \\
\hline 79 & fish & 3 & 2.2122 & 6.26 & 1 & 212 & catch & guide \\
\hline 80 & cannon & 5 & 0.7782 & 6.05 & 0.95 & 183 & blast & shoe \\
\hline 81 & shoe & 2 & 1.8976 & 6.47 & 1 & 150 & sock & owl \\
\hline 82 & sandwich & 7 & 1 & 6.34 & 0.9 & 238 & bread & aim \\
\hline 83 & spider & 6 & 0.8451 & 6.54 & 1 & 290 & web & cough \\
\hline 84 & belt & 4 & 1.4314 & 6.24 & 1 & 211 & pants & nasal \\
\hline 85 & toilet & 5 & 1.4472 & 6.5 & 1 & 182 & flush & calf \\
\hline 86 & wagon & 5 & 1.0414 & 5.43 & 1 & 279 & pull & add \\
\hline 87 & ruler & 5 & 1.2553 & 6.03 & 1 & 88 & measure & married \\
\hline 88 & tractor & 7 & 1.0414 & 6.29 & 0.95 & 206 & farmer & stomach \\
\hline 89 & queen & 4 & 1.7243 & 6.16 & 1 & 354 & king & edge \\
\hline 90 & train & 4 & 1.9085 & 6.42 & 1 & 368 & railroad & blanket \\
\hline 91 & church & 4 & 2.2625 & 6.45 & 1 & 340 & steeple & monkey \\
\hline 92 & anchor & 5 & 0.7782 & 6.18 & 1 & 221 & boat & cool \\
\hline 93 & whistle & 5 & 0.9542 & 5.58 & 0.9 & 158 & blow & cape \\
\hline 94 & corn & 4 & 1.3802 & 5.26 & 1 & 235 & husk & chess \\
\hline 95 & pyramid & 7 & 0.8451 & 6.43 & 0.95 & 298 & Egypt & tulip \\
\hline 96 & typewriter & 8 & 1.0414 & 6 & 1 & 289 & secretary & automobile \\
\hline 97 & rope & 3 & 1.6232 & 6.08 & 1 & 303 & knot & dent \\
\hline 98 & basket & 6 & 1.3802 & 5.87 & 1 & 300 & picnic & predict \\
\hline 99 & letter & 5 & 2.3139 & 5.66 & 1 & 299 & stamp & tap \\
\hline
\end{tabular}




\begin{tabular}{|c|c|c|c|c|c|c|c|c|}
\hline 100 & nose & 3 & 1.9085 & 6.21 & 1 & 59 & snot & corn \\
\hline 101 & chimney & 5 & 1 & 6.24 & 0.95 & 331 & fireplace & dedicate \\
\hline 102 & horse & 4 & 2.1206 & 6.5 & 1 & 232 & saddle & spoken \\
\hline 103 & key & 2 & 1.9345 & 6.08 & 1 & 160 & lock & tie \\
\hline 104 & fireman & 6 & 0.6021 & 6.13 & 1 & 237 & rescue & harvest \\
\hline 105 & cross & 4 & 1.3424 & 5.47 & 1 & 100 & holy & bus \\
\hline 106 & crutches & 4 & 0.6021 & 6.13 & 1 & 210 & walk & sleep \\
\hline 107 & bone & 3 & 1.8388 & 5.92 & 1 & 164 & skeleton & dominate \\
\hline 108 & cat & 3 & 1.8261 & 6.66 & 1 & 171 & meow & hose \\
\hline 109 & kitchen & 5 & 2.0453 & 6.08 & 1 & 348 & apron & strategy \\
\hline 110 & dragon & 6 & 0.9542 & 6.13 & 1 & 394 & puff & tart \\
\hline 111 & saddle & 5 & 1 & 5.79 & 0.9 & 201 & horse & fine \\
\hline 112 & pie & 2 & 1.2304 & 6.13 & 1 & 156 & crust & ache \\
\hline 113 & snail & 4 & 0.6021 & 6.47 & 1 & 154 & shell & van \\
\hline 114 & pirate & 5 & 0.699 & 6.45 & 1 & 464 & capture & rental \\
\hline 115 & clock & 4 & 1.5911 & 6.47 & 1 & 283 & time & head \\
\hline 116 & pumpkin & 7 & 0.301 & 6.45 & 1 & 200 & Halloween & determine \\
\hline 117 & sock & 3 & 1.2553 & 6.24 & 1 & 110 & shoe & $\operatorname{tin}$ \\
\hline 118 & closet & 6 & 1.0414 & 5.16 & 1 & 247 & hanger & bullet \\
\hline 119 & hair & 3 & 2.2989 & 6.13 & 1 & 458 & brush & tape \\
\hline 120 & baby & 4 & 2.4116 & 6.24 & 1 & 177 & crib & hook \\
\hline 121 & bat & 3 & 1.1461 & 5.84 & 1 & 180 & vampire & purely \\
\hline 122 & leaf & 3 & 1.9085 & 6.18 & 1 & 144 & maple & monster \\
\hline 123 & slippers & 6 & 0.9542 & 6.05 & 0.75 & 123 & feet & read \\
\hline 124 & mountain & 6 & 1.9243 & 6.37 & 0.95 & 270 & climber & garbage \\
\hline 125 & sun & 3 & 2.1818 & 6.63 & 0.9 & 218 & rays & shy \\
\hline 126 & moustache & 6 & 0 & 6.16 & 1 & 216 & beard & hen \\
\hline 127 & ear & 2 & 1.9445 & 6.32 & 1 & 161 & lobe & harp \\
\hline 128 & door & 3 & 2.5866 & 6.24 & 1 & 266 & knob & peel \\
\hline 129 & house & 3 & 2.7825 & 6.45 & 0.95 & 179 & brick & dish \\
\hline 130 & nail & 3 & 1.3979 & 6.05 & 1 & 81 & hammer & sofa \\
\hline 131 & binoculars & 11 & 0.699 & 6.24 & 0.9 & 188 & birds & wig \\
\hline 132 & celery & 6 & 0.4771 & 5.68 & 0.75 & 233 & stalk & ring \\
\hline 133 & vase & 3 & 0.8451 & 5.86 & 1 & 203 & flower & motor \\
\hline 134 & pencil & 6 & 1.2788 & 6.34 & 1 & 136 & eraser & unspeakable \\
\hline 135 & elephant & 7 & 1.3802 & 6.63 & 1 & 233 & tusk & fold \\
\hline 136 & hose & 3 & 0.6021 & 5.84 & 1 & 229 & garden & vision \\
\hline 137 & bench & 4 & 1.415 & 5.92 & 1 & 290 & park & text \\
\hline 138 & zebra & 5 & 0.301 & 6.59 & 1 & 286 & stripe & eel \\
\hline 139 & $\operatorname{man}$ & 3 & 3.2119 & 5.82 & 0.95 & 189 & lady & ship \\
\hline 140 & seal & 3 & 1.1461 & 5.82 & 0.9 & 171 & walrus & apple \\
\hline 141 & wig & 3 & 1.1139 & 5.58 & 1 & 217 & hair & rock \\
\hline 142 & necklace & 6 & 0.6021 & 6.32 & 1 & 136 & pearl & wing \\
\hline 143 & desk & 4 & 1.959 & 5.95 & 0.95 & 238 & office & water \\
\hline 144 & bell & 3 & 1.6232 & 6.08 & 1 & 151 & chime & hair \\
\hline 145 & star & 4 & 2.0043 & 5.95 & 1 & 114 & astronomy & graduation \\
\hline 146 & hammer & 5 & 1.0414 & 6.32 & 1 & 133 & nail & ape \\
\hline 147 & pillow & 4 & 1.2788 & 6.24 & 1 & 115 & sheets & spoon \\
\hline 148 & spoon & 4 & 1.1761 & 6.34 & 1 & 142 & fork & wool \\
\hline 149 & zipper & 5 & 0.301 & 5.84 & 0.95 & 95 & button & daisy \\
\hline 150 & top & 3 & 2.2355 & 3.95 & 0.95 & 120 & spin & tame \\
\hline 151 & flower & 6 & 1.9685 & 6.29 & 1 & 214 & petals & bullet \\
\hline 152 & kite & 3 & 0.699 & 6.11 & 1 & 158 & flying & sleeping \\
\hline 153 & suit & 3 & 1.716 & 5.92 & 1 & 201 & tie & hen \\
\hline 154 & cake & 3 & 1.5315 & 6.55 & 1 & 185 & icing & invest \\
\hline 155 & hat & 3 & 1.8325 & 6.39 & 1 & 128 & coat & moon \\
\hline 156 & crown & 4 & 1.3802 & 6.08 & 1 & 318 & throne & eel \\
\hline
\end{tabular}




\begin{tabular}{|c|c|c|c|c|c|c|c|c|}
\hline 157 & piano & 5 & 1.4314 & 6.42 & 0.95 & 305 & music & single \\
\hline 158 & stethoscope & 9 & 0 & 6.13 & 1 & 172 & doctor & window \\
\hline 159 & bride & 4 & 1.0792 & 6.24 & 0.94 & 396 & groom & tin \\
\hline 160 & butterfly & 8 & 1 & 6.35 & 1 & 421 & cocoon & scored \\
\hline 161 & heart & 4 & 2.2148 & 6.13 & 1 & 101 & valentine & jockey \\
\hline 162 & skis & 3 & 0.9031 & 6 & 1 & 216 & slope & pie \\
\hline 163 & clown & 4 & 0.6021 & 6.11 & 1 & 398 & circus & filter \\
\hline 164 & volcano & 7 & 0.7782 & 6.49 & 1 & 366 & erupt & boxer \\
\hline 165 & pear & 3 & 0.7782 & 6.47 & 1 & 84 & fruit & bus \\
\hline 166 & octopus & 7 & 0.301 & 6.39 & 1 & 392 & tentacles & recording \\
\hline 167 & saw & 2 & 0 & 5.79 & 1 & 121 & chain & bird \\
\hline 168 & camera & 6 & 1.5563 & 6.32 & 1 & 231 & tourist & harvest \\
\hline 169 & bed & 3 & 2.4298 & 6.58 & 1 & 192 & sleep & fort \\
\hline 170 & harp & 4 & 0.4771 & 6.08 & 0.94 & 223 & music & single \\
\hline 171 & broom & 4 & 0.9031 & 6.13 & 0.9 & 181 & sweep & thaw \\
\hline 172 & nurse & 4 & 1.6902 & 6.11 & 1 & 189 & doctor & colour \\
\hline 173 & eye & 1 & 2.7185 & 6.42 & 1 & 221 & sight & thin \\
\hline 174 & cowboy & 4 & 0.7782 & 5.89 & 0.95 & 227 & horse & book \\
\hline 175 & monkey & 5 & 1.2553 & 6.55 & 1 & 188 & banana & rejection \\
\hline
\end{tabular}




\section{APPENDIX B}

This Appendix provides details of additional models we ran following the recommendation of the reviewers with random intercepts and correlated random slopes (reported below). These models do not change the key findings, with the only difference being that the main effect for Frequency was no longer significant. Note the perfect correlations between intercepts and slopes, indicating that the addition of slopes are not explaining additional variance in the model. No intercept was included for imageability as models including both intercepts and slopes for imageability did not converge.

Model refit with data points excluded that had residuals $>2.5$ standard deviations

\begin{tabular}{|c|c|c|c|c|c|}
\hline Fixed Effects & Estimate & $\begin{array}{c}\text { Standard } \\
\text { Error }\end{array}$ & $\begin{array}{c}\text { Wald 95\% } \\
\text { CI }\end{array}$ & $\mathbf{Z}$ & $p$ \\
\hline Intercept & 0.30 & 0.55 & $-0.78-1.37$ & 0.54 & 0.59 \\
\hline $\begin{array}{l}\text { Phonological Cue vs No Phonological } \\
\text { Cue }\end{array}$ & & & $063-101$ & & \\
\hline $\begin{array}{l}\text { Cue } \\
\text { Length }\end{array}$ & $\begin{array}{c}0.82 \\
-0.50\end{array}$ & $\begin{array}{l}0.10 \\
0.09\end{array}$ & $\begin{array}{r}0.63-1.01 \\
-0.68--0.32\end{array}$ & $\begin{array}{r}8.56 \\
-5.38\end{array}$ & $\begin{array}{l}\mathrm{p}<0.001^{*} \\
\mathrm{p}<0.001 *\end{array}$ \\
\hline Frequency & 0.23 & 0.11 & $0.03-0.44$ & 2.22 & $\mathrm{p}=0.03 *$ \\
\hline Imageability & 0.36 & 0.11 & $0.15-0.56$ & 3.37 & $\mathrm{p}<0.005^{*}$ \\
\hline Name Agreement & 0.18 & 0.07 & $0.05-0.31$ & 2.68 & $\mathrm{p}=0.007^{*}$ \\
\hline $\begin{array}{l}\text { Visual Complexity x Phonological Cue } \\
\text { Visual Complexity x No Phonological }\end{array}$ & -0.33 & 0.12 & $-0.57--0.09$ & -2.74 & $\mathrm{p}=0.006^{*}$ \\
\hline Cue & -0.16 & 0.09 & $-0.35-0.02$ & -1.71 & $\mathrm{p}=0.09$ \\
\hline Random Effects & & Variance & SD & Correlation & \\
\hline \multicolumn{6}{|l|}{ Intercepts } \\
\hline Items & & 0.52 & 0.72 & & \\
\hline Participants & & 2.75 & 1.66 & & \\
\hline \multicolumn{6}{|l|}{ Slopes (varying over Participants) } \\
\hline Condition Phonological & & 0.67 & 0.82 & & \\
\hline Condition Semantic & & 0.14 & 0.38 & 0.99 & \\
\hline Length & & 0.03 & 0.16 & & \\
\hline Frequency & & 0.06 & 0.24 & & \\
\hline Imageability & & 0.06 & 0.25 & & \\
\hline $\begin{array}{l}\text { Visual Complexity x Phonological Cue } \\
\text { Visual Complexity x NoPhonological }\end{array}$ & & 0.06 & 0.24 & 1.00 & \\
\hline Cue & & 0.04 & 0.20 & & \\
\hline
\end{tabular}

"R model equation: ACC $\sim(1 \mid$ Subject $)+(1 \mid$ Word $)+(0+$ Condition $\mid$ Subject $)+$

$(0+$ zLengthPh $\mid$ Subject $)+(0+$ zFreq $\mid$ Subject $)+(0+$ zImageability $\mid$ Subject $)+(0+$ PhCue:zVisComp $\mid$ Subject $)+$ PhCue + zLengthPh + zFreq + zImageability + zNameAgr + PhCue:zVisComp" Confidence intervals calculated with confint.merMod() function in lme 4

Following Baayen \& Milin (2010), we looked at the number of data points for which standardised residuals were greater than 2.5 or less than -2.5 ; there were 38 such data points. The advice in Baayen \& Milin is to refit a model after removing data points for there are large residuals $(>2.5)$. If the model parameters and coefficients are the similar following refitting, we can argue that findings in the original model were not overly influenced by outliers or data points leveraging model estimates. 


\section{APPENDIX C}

Maximal model (random intercepts and correlated random slopes)

\begin{tabular}{|c|c|c|c|c|c|}
\hline \multirow[b]{2}{*}{ Fixed Effects } & \multicolumn{3}{|c|}{ Standard } & \multirow[b]{2}{*}{$\mathbf{Z}$} & \multirow[b]{2}{*}{$p$} \\
\hline & Estimate & Error & 95\% CI & & \\
\hline Intercept & 0.30 & 0.43 & $-0.88-1.51$ & 0.71 & 0.48 \\
\hline Phonological Cue vs No Phonological Cue & 0.65 & 0.09 & $0.42-0.88$ & 7.50 & $\mathrm{p}<0.001 *$ \\
\hline Length & -0.39 & 0.08 & $-0.59--0.19$ & -5.21 & $\mathrm{p}<0.001 *$ \\
\hline Frequency & 0.15 & 0.09 & $-0.09-0.40$ & 1.63 & $\mathrm{p}=0.10$ \\
\hline Imageability & 0.26 & 0.08 & $0.05-0.47$ & 3.42 & $\mathrm{p}<0.001 *$ \\
\hline Name Agreement & 0.15 & 0.06 & $0.00-0.30$ & 2.74 & $\mathrm{p}=0.006^{*}$ \\
\hline Visual Complexity x Phonological Cue & -0.25 & 0.10 & $-0.53-0.03$ & -2.42 & $\mathrm{p}=0.02^{*}$ \\
\hline Visual Complexity x No Phonological Cue & -0.11 & 0.07 & $-0.30-0.07$ & -1.60 & $\mathrm{p}=0.11$ \\
\hline Random Effects & & Variance & SD & Correlation & \\
\hline \multicolumn{6}{|l|}{ Intercepts } \\
\hline Items & & 0.32 & 0.56 & & \\
\hline \multicolumn{6}{|l|}{ Participant Intercepts \& Slopes } \\
\hline Participant x Condition (intercept) & & 0.27 & 0.52 & & \\
\hline Condition (slope) & & 0.12 & 0.35 & -1.00 & \\
\hline Participant $x$ Length (intercept) & & 0.29 & 0.54 & & \\
\hline Length (slope) & & 0.16 & 0.13 & -1.00 & \\
\hline Participant x Frequency (intercept) & & 1.45 & 1.20 & & \\
\hline Frequency (slope) & & 0.05 & 0.22 & -1.00 & \\
\hline Imageability (slope) & & 0.03 & 0.17 & & \\
\hline Participant x Name Agreement (intercept) & & 0.00 & 0.00 & & \\
\hline Name Agreement (slope) & & 0.00 & 0.00 & 1.00 & \\
\hline $\begin{array}{l}\text { Participant x Visual Complexity x } \\
\text { Phonological Cue (intercept) } \\
\text { Visual Complexity x Phonological Cue }\end{array}$ & & 0.01 & 0.10 & & \\
\hline (slope) & & 0.04 & 0.20 & 1.00 & \\
\hline Visual Complexity x NoPhonological Cue (s & pe) & 0.01 & 0.12 & 1.00 & 1.00 \\
\hline
\end{tabular}

R model equation: Accuracy $\sim(1+$ Condition $\mid$ Subject $)+(1 \mid$ Word $)+(1+$ zLengthPh $\mid$

Subject $)+(1+$ zFreq $\mid$ Subject $)+(0+$ zImageability $\mid$ Subject $)+(1+$ zNameAgr $\mid$ Subject $)+(1+$

PhCue:zVisComp | Subject $)+$ PhCue + zLengthPh + zFreq + zImageability + zNameAgr + PhCue:zVisComp

Confidence intervals calculated with confint.merMod() function in lme4 